\title{
The Systematic Component of Monetary Policy in SVARs: An Agnostic Identification Procedure
}

Arias, Jonas E., Dario Caldara, and Juan F. Rubio-Ramirez

Please cite paper as:

Arias, Jonas E., Dario Caldara, and Juan F. Rubio-Ramirez

(2015). The Systematic Component of Monetary Policy in

SVARs: An Agnostic Identification Procedure.

International Finance Discussion Papers 1131.

http://dx.doi.org/10.17016/IFDP.2015.1131

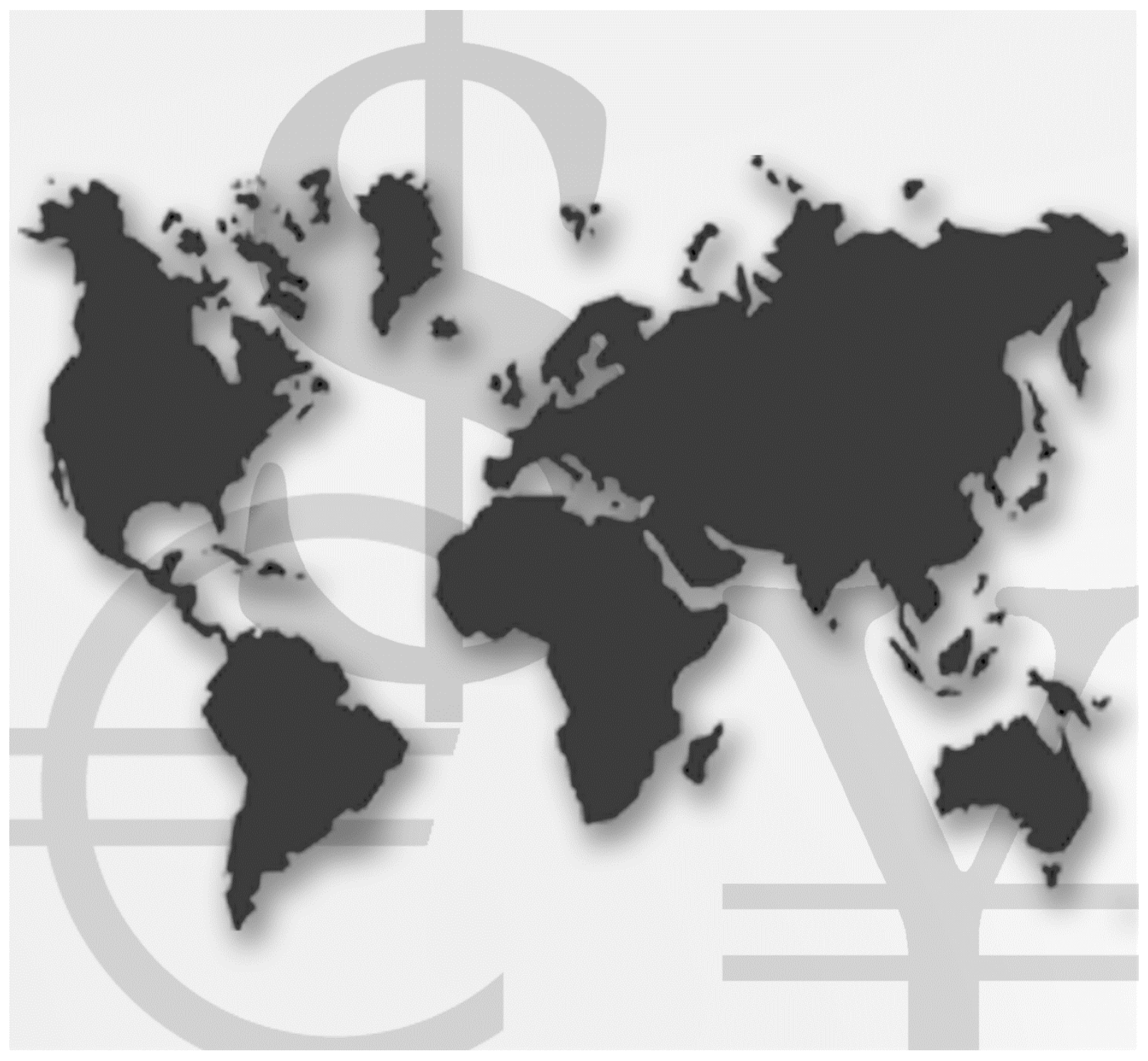

\section{International Finance Discussion Papers}

Board of Governors of the Federal Reserve System

Number 1131

March 2015 
Board of Governors of the Federal Reserve System

International Finance Discussion Papers

Number 1131

March, 2015

\title{
The Systematic Component of Monetary Policy in SVARs: An Agnostic Identification Procedure
}

\author{
Jonas E. Arias, Dario Caldara, and Juan F. Rubio-Ramirez
}

NOTE: International Finance Discussion Papers are preliminary materials circulated to stimulate discussion and critical comment. References to International Finance Discussion Papers (other than an acknowledgment that the writer has had access to unpublished material) should be cleared with the author or authors. Recent IFDPs are available on the Web at www.federalreserve.gov/pubs/ifdp/. This paper can be downloaded without charge from Social Science Research Network electronic library at wWw.ssrn.com. 


\title{
The Systematic Component of Monetary Policy in SVARs: An Agnostic Identification Procedure
}

\author{
Jonas E. Arias \\ Dario Caldara \\ Federal Reserve Board \\ Federal Reserve Board \\ Juan F. Rubio-Ramírez* \\ Duke University, BBVA Research, and Federal Reserve Bank of Atlanta
}

March 12, 2015

\begin{abstract}
Following Leeper, Sims, and Zha (1996), we identify monetary policy shocks in SVARs by restricting the systematic component of monetary policy. In particular, we impose sign and zero restrictions only on the monetary policy equation. Since we do not restrict the response of output to a monetary policy shock, we are agnostic in Uhlig]s (2005) sense. But, in contrast to Uhlig (2005), our results support the conventional view that a monetary policy shock leads to a decline in output. Hence, our results show that the contractionary effects of monetary policy shocks do not hinge on questionable exclusion restrictions.
\end{abstract}

JEL classification: E52; C51

Keywords: SVARs; Monetary policy shocks; Systematic component of monetary policy

\footnotetext{
*Corresponding author: Juan F. Rubio-Ramírez < juan.rubio-ramirez@duke.edu>, Economics Department, Duke University, Durham, NC 27708; 1-919-660-1865. We thank conference and seminar participants at the 2014 Paris Workshop on Empirical Monetary Economics, Board of Governors of the Federal Reserve System, Federal Reserve Bank of Atlanta, Federal Reserve Bank of New York, Federal Reserve Bank of Philadelphia, Institute for Economic Analysis at the Universitat Autonoma de Barcelona, IMF, Macro Midwest Meeting Fall 2014, North Carolina State University, System Conference in Macroeconomics Fall 2014, and the University of Pennsylvania for comments and discussions, especially Tony Braun, Frank Diebold, Pablo Guerron-Quintana, Matteo Iacoviello, Jesper Linde, John Roberts, Frank Schorfheide, Enrique Sentana, Pedro Silos, Paolo Surico, Mathias Trabandt, Harald Uhlig, Rob Vigfusson, Daniel Waggoner, and Tao Zha. We also thank Mazi Kazemi for valuable research assistance. The views expressed here are the authors' and do not necessarily represent those of the Federal Reserve Bank of Atlanta or the Board of Governors of the Federal Reserve System. Juan F. Rubio-Ramírez acknowledges financial support from National Science Foundation, Foundation Banque de France pour la Recherche, the Institute for Economic Analysis (IAE), the "Programa de Excelencia en Educacion e Investigacion" of the Bank of Spain, and the Spanish ministry of science and technology Ref. ECO2011-30323-c03-01.
} 


\section{Introduction}

Following Sims $(1972,1980,1986)$, researchers have analyzed the effects of monetary policy on output using structural vector autoregressions (SVARs). Most have concluded that an increase in the federal funds rate or a decrease in the money supply are contractionary - they have a significant negative effect on output. Studies supporting this view include Bernanke and Blinder (1992); Christiano, Eichenbaum, and Evans (1996); Leeper, Sims, and Zha (1996); and Bernanke and Mihov (1998)! This intuitive result has become the cornerstone rationale behind New Keynesian dynamic stochastic general equilibrium (DSGE) models. Researchers also estimate New Keynesian models by matching the model implied dynamic responses to a monetary policy shock with those implied by a SVAR - see Rotemberg and Woodford (1997) and Christiano, Eichenbaum, and Evans (2005).

The consensus on the contractionary effects of monetary policy shocks on output has been challenged by Uhlig (2005), who found no evidence to support such a view using an agnostic identification strategy. The essence of Uhlig's (2005) critique is that the consensus is based on the traditional SVAR approach in which the researcher needs to impose a questionable zero restriction on the response of output after a monetary policy shock. Uhlig (2005) therefore proposes to identify monetary policy shocks by imposing sign restrictions only on the impulse response functions of prices and nonborrowed reserves to monetary policy shocks. Uhlig (2005) labels his identification scheme as agnostic because no restrictions are imposed on the response of output to the monetary policy shock. The scheme only eliminates the well-known price and liquidity puzzles ${ }^{2}$ Furthermore, since the identification strategy only imposes a few sign restrictions on the impulse response functions to a monetary policy shock, using the language in Inoue and Kilian (2013), Uhlig (2005) set and partially identifies the model, while the traditional SVARs exactly and fully identify it $3^{3}$ This means that Uhlig]s (2005) identification strategy does not identify a single model but rather a set of models

\footnotetext{
${ }^{1}$ Leeper, Sims, and Zha (1996); Bagliano and Favero (1998); and Christiano, Eichenbaum, and Evans (1999) survey this extensive literature.

${ }^{2}$ See Sims (1992) for a description of the price puzzle, and Leeper and Gordon (1992) for a description of the liquidity puzzle.

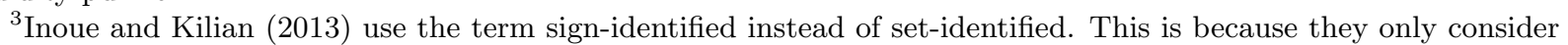
sign restrictions. Since we will consider both sign and zero restrictions, we prefer to use the term set-identified. Inoue and Kilian (2013) use the term partially identified when only a subset of structural shocks are identified, while fully identified refers to models where all of the shocks are identified.
} 
that are coherent with the sign restrictions. This is an appealing feature because it implies that his results are robust to a wide range of models (those that satisfy his sign restrictions), not tied to a single one.

In this paper, we endorse the agnostic identification approach - we do not impose restrictions on the response of output to a monetary policy shock - but instead of imposing sign restrictions on some of the impulse response functions to a monetary policy shock, we restrict the monetary policy equation. Specifically, our identification strategy imposes sign and zero restrictions on the systematic component of monetary policy. Our strategy is inspired by Leeper, Sims, and Zha (1996); Leeper and Zha (2003); and Sims and Zha (2006a), who emphasize the need to specify and estimate monetary policy equations. Policy choices in general, and monetary policy choices in particular, do not evolve independently of economic conditions: "Even the harshest critics of monetary authorities would not maintain that policy decisions are unrelated to the economy" (Leeper, Sims, and Zha (1996); p. 1). Thus, to isolate exogenous changes in policy, one needs to model how policy reacts to the economy.

We identify monetary policy shocks by imposing sign and zero restrictions on the systematic component of monetary policy. We propose two identification schemes - that is, two sets of sign and zero restrictions - inspired by two specifications of the systematic component of monetary policy that are prevalent in the literature. The first set of restrictions, which forms our baseline identification approach, implies a specification of the systematic component of monetary policy where the federal funds rate only responds to output and prices, and this response is positive. The baseline identification scheme parallels traditional SVARs, such as the one prominently used by Christiano, Eichenbaum, and Evans (1996), and is consistent with Taylor-type rules widely used in DSGE models. Furthermore, our baseline identification scheme is also consistent with Romer and Romer (2004). The second set of restrictions, which forms our alternative identification approach, implies a specification of the systematic component of monetary policy that is related to the class of money rules described in Leeper, Sims, and Zha (1996); Leeper and Zha (2003); and Sims and Zha (2006a b). In contrast to these papers, we set and partially identify the model. Hence, both our baseline and alternative identification approaches share two important features with Uhlig]s (2005) approach. First, we do not impose any restriction on the response of output to monetary 
shocks (we remain agnostic about this response), and second, we do not identify a single model but rather a set of models that are coherent with our sign and zero restrictions.

We highlight two results. First, we find that an exogenous tightening of monetary policy has contractionary effects on output in both the baseline and the alternative identification schemes, and that prices mostly decline following a monetary policy shock even though we do not impose restrictions on their response to this shock. The decline in real activity and prices causes a mediumterm loosening of the monetary policy stance. Therefore, our agnostic identification schemes recover the consensus regarding the effects of monetary policy shocks on output while addressing Uhlig (2005)'s critique, as we do not impose any questionable exclusion restrictions. Hence, we show that an agnostic identification approach does not necessarily rule out the consensus. This result survives several robustness exercises.

Second, we show that the identification scheme in Uhlig (2005) violates our restrictions on the systematic component of monetary policy. This is the case for both the baseline and the alternative identification schemes. Following Leeper, Sims, and Zha (1996); Leeper and Zha (2003); and Sims and Zha (2006a), a corollary to our findings is that the shocks identified in Uhlig (2005) are not monetary policy shocks because the systematic component of monetary policy is counterfactual and thus does not correctly control for the endogenous response of monetary policy to economic activity.

To further understand the relationship between our baseline and Uhlig s (2005) identification approach, we combine the sign restrictions on impulse response functions in Uhlig (2005) with the set of sign and zero restrictions on the systematic component that characterize our baseline identification scheme. We find that our restrictions substantially shrink the set of models originally identified by Uhlig (2005). The exclusion of models with counterfactual monetary policy equations suffices to generate a negative response of output and thereby to recover the consensus. We find that the sign restriction on the response of the federal funds rate to output is crucial to this result. The restrictions in Uhlig (2005) also shrink the set of admissible models obtained using our baseline identification scheme, as they exclude models that generate the price and liquidity puzzles. But this refinement has only a modest impact on our results. We obtain a similar outcome when using the alternative identification scheme.

Our work is related to several studies in the literature. A similar identification strategy to the 
one used in this paper is employed by Caldara and Kamps (2012), who identify tax and government spending shocks by putting discipline on the systematic component of fiscal policy. They combine zero restrictions with empirically plausible bounds on the output elasticities of fiscal variables. Arias, Rubio-Ramirez, and Waggoner (2014) develop the theoretical foundation to identify SVARs by jointly imposing sign and zero restrictions extending the work of Faust (1998), Uhlig (2005), and Rubio-Ramírez, Waggoner, and Zha (2010). They apply their methodology to revisit the identification of optimism shocks in Beaudry, Nam, and Wang (2011) and the identification of fiscal shocks in Mountford and Uhlig (2009). Both applications impose restrictions on impulse response functions, whereas we apply their methodology to impose restrictions directly on the SVAR equations. We also study identification schemes that combine restrictions on the SVAR equations with restrictions on impulse response functions. Some recent applications of SVAR identification based on sign and zero restrictions on impulse response functions include Baumeister and Benati (2010), who identify the effects of unconventional monetary policy; Binning (2013), who identifies anticipated government spending shocks; and Peersman and Wagner (2014), who identify shocks to bank lending. Baumeister and Hamilton (2014) study how informative the data are relative to the prior distributions on the structural parameters in the estimation of SVARs identified using sign restrictions.

The structure of this paper is as follows. In Section 2, we describe the SVAR methodology and describe our baseline identification scheme. In Section 3, we describe the results of our baseline identification scheme and compare them with Uhlig (2005) and Christiano, Eichenbaum, and Evans (1996). In Section 4, we consider some robustness exercises around the specification of the monetary policy equation that motivates our baseline identification scheme. In Section 5, we present the results from our alternative identification approach. In Section 6, we conclude.

\section{Methodology}

Let us consider the following SVAR:

$$
\mathbf{y}_{t}^{\prime} \mathbf{A}_{0}=\sum_{\ell=1}^{p} \mathbf{y}_{t-\ell}^{\prime} \mathbf{A}_{\ell}+\mathbf{c}+\varepsilon_{t}^{\prime} \quad \text { for } 1 \leq t \leq T,
$$


where $\mathbf{y}_{t}$ is an $n \times 1$ vector of endogenous variables, $\varepsilon_{t}$ is an $n \times 1$ vector of structural shocks, $\mathbf{A}_{\ell}$ is an $n \times n$ matrix of structural parameters for $0 \leq \ell \leq p$ with $\mathbf{A}_{0}$ invertible, $\mathbf{c}$ is a $1 \times n$ vector of parameters, $p$ is the lag length, and $T$ is the sample size. The vector $\varepsilon_{t}$, conditional on past information and the initial conditions $\mathbf{y}_{0}, \ldots, \mathbf{y}_{1-p}$, is Gaussian with mean zero and covariance matrix $\mathbf{I}_{n}$ (the $n \times n$ identity matrix). The model described in equation (1) can be written as

$$
\mathbf{y}_{t}^{\prime} \mathbf{A}_{0}=\mathbf{x}_{t}^{\prime} \mathbf{A}_{+}+\varepsilon_{t}^{\prime} \quad \text { for } 1 \leq t \leq T,
$$

where $\mathbf{A}_{+}^{\prime}=\left[\begin{array}{llll}\mathbf{A}_{1}^{\prime} & \cdots & \mathbf{A}_{p}^{\prime} & \mathbf{c}^{\prime}\end{array}\right]$ and $\mathbf{x}_{t}^{\prime}=\left[\begin{array}{llll}\mathbf{y}_{t-1}^{\prime} & \cdots & \mathbf{y}_{t-p}^{\prime} & 1\end{array}\right]$ for $1 \leq t \leq T$. The dimension of $\mathbf{A}_{+}$is $m \times n$, where $m=n p+1$. We call $\mathbf{A}_{0}$ and $\mathbf{A}_{+}$the structural parameters. The reduced-form vector autoregression (VAR) model implied by equation (2) is

$$
\mathbf{y}_{t}^{\prime}=\mathbf{x}_{t}^{\prime} \mathbf{B}+\mathbf{u}_{t}^{\prime} \quad \text { for } 1 \leq t \leq T
$$

where $\mathbf{B}=\mathbf{A}_{+} \mathbf{A}_{0}^{-1}, \mathbf{u}_{t}^{\prime}=\varepsilon_{t}^{\prime} \mathbf{A}_{0}^{-1}$, and $\mathbb{E}\left[\mathbf{u}_{t} \mathbf{u}_{t}^{\prime}\right]=\boldsymbol{\Sigma}=\left(\mathbf{A}_{0} \mathbf{A}_{0}^{\prime}\right)^{-1}$. Finally, the impulse response functions (IRFs) are defined as follows.

Definition 1. Let $\left(\mathbf{A}_{0}, \mathbf{A}_{+}\right)$be any value of structural parameters: The IRF of the $i$-th variable to the $j$-th structural shock at finite horizon $h$ corresponds to the element in row $i$ and column $j$ of the matrix

$$
\mathbf{L}_{h}\left(\mathbf{A}_{0}, \mathbf{A}_{+}\right)=\left(\mathbf{A}_{0}^{-1} \mathbf{J}^{\prime} \mathbf{F}^{h} \mathbf{J}\right)^{\prime} \text {, where } \mathbf{F}=\left[\begin{array}{cccc}
\mathbf{A}_{1} \mathbf{A}_{0}^{-1} & \mathbf{I}_{n} & \cdots & \mathbf{0} \\
\vdots & \vdots & \ddots & \vdots \\
\mathbf{A}_{p-1} \mathbf{A}_{0}^{-1} & \mathbf{0} & \cdots & \mathbf{I}_{n} \\
\mathbf{A}_{p} \mathbf{A}_{0}^{-1} & \mathbf{0} & \cdots & \mathbf{0}
\end{array}\right] \text { and } \mathbf{J}=\left[\begin{array}{c}
\mathbf{I}_{n} \\
\mathbf{0} \\
\vdots \\
\mathbf{0}
\end{array}\right]
$$

\subsection{Set Identification by Sign and Zero Restrictions on $A_{0}$}

Most of the papers in the literature involving set identification impose sign restrictions on the IRFs. Instead, both of our identification approaches (the baseline and the alternative) combine sign and zero restrictions on $\mathbf{A}_{\mathbf{0}}$, which we use to discipline the systematic component of monetary policy. To relate our paper to the existing literature, we also examine two additional identification schemes. 
The first one only imposes sign restrictions on IRFs, as Uhlig (2005) does, and the second one imposes sign restrictions on IRFs and sign and zero restrictions on $\mathbf{A}_{\mathbf{0}} 4^{4}$ Accordingly, our paper shows that it is possible to impose sign and zero restrictions on IRFs and $\mathbf{A}_{\mathbf{0}}$, which is relevant since, in general, the literature concentrates on either one or the other.

The methodology we use to implement our proposed identification approaches is based on Arias, Rubio-Ramirez, and Waggoner (2014). While we refer the reader to their paper for details, it is useful to summarize the characterization of the sign and zero restrictions as follows. Let us assume that we want to impose sign and zero restrictions on some elements of $\mathbf{A}_{\mathbf{0}}$ and on some IRFs at different horizons. It is convenient to stack $\mathbf{A}_{\mathbf{0}}$ and the IRFs for all the relevant horizons into a single matrix of dimension $k \times n$, which we denote by $f\left(\mathbf{A}_{0}, \mathbf{A}_{+}\right)$. For example, if we impose restrictions on IRFs at horizons zero and one, then

$$
f\left(\mathbf{A}_{0}, \mathbf{A}_{+}\right)=\left[\begin{array}{c}
\mathbf{A}_{\mathbf{0}} \\
\mathbf{L}_{0}\left(\mathbf{A}_{0}, \mathbf{A}_{+}\right) \\
\mathbf{L}_{1}\left(\mathbf{A}_{0}, \mathbf{A}_{+}\right)
\end{array}\right], \text {where } k=3 n \text { in this case. }
$$

We represent the sign restrictions on $f\left(\mathbf{A}_{0}, \mathbf{A}_{+}\right)$used to identify structural shock $j$ by a matrix $\mathbf{S}_{j}$, where the number of columns in $\mathbf{S}_{j}$ is equal to $k$ and $1 \leq j \leq n$. $\mathbf{S}_{j}$ is a selection matrix and thus has one non-zero entry in each row. If the rank of $\mathbf{S}_{j}$ is $s_{j}$, then $s_{j}$ is the number of sign restrictions imposed to identify the $j$-th structural shock. Similarly, we represent the zero restrictions on $f\left(\mathbf{A}_{0}, \mathbf{A}_{+}\right)$used to identify structural shock $j$ by a selection matrix $\mathbf{Z}_{j}$, where the number of columns in $\mathbf{Z}_{j}$ is also equal to $k$ and each row has one non-zero entry. If the rank of $\mathbf{Z}_{j}$ is $z_{j}$, then $z_{j}$ is the number of zero restrictions imposed to identify the $j$-th structural shock.

The characterization is general enough to encompass the four cases described previously: (1) sign and zero restrictions on $\mathbf{A}_{\mathbf{0}}$, (2) sign restrictions on IRFs, (3) sign restrictions on IRFs and sign and zero restrictions on $\mathbf{A}_{\mathbf{0}}$, and (4) sign and zero restrictions on IRFs and $\mathbf{A}_{\mathbf{0}}$. Moreover, although our baseline and alternative identification approaches partially identify the model, the methodology can be used to fully identify it.

With the characterization at hand, we draw from the posterior distribution of the structural

\footnotetext{
${ }^{4}$ In this section, it will become evident that we could also consider the case of sign and zero restrictions on both IRFs and $\mathbf{A}_{\mathbf{0}}$.
} 
parameters that satisfies the sign and zero restrictions using the algorithm described in Arias, Rubio-Ramirez, and Waggoner (2014), which we reproduce below.

\section{Algorithm 1.}

1. Draw $\left(\mathbf{A}_{0}, \mathbf{A}_{+}\right)$from the posterior distribution of the structural parameters conditional on the zero restrictions.

2. Keep the draw if the sign restrictions are satisfied.

3. Return to Step 1 until the required number of draws from the posterior distribution conditional on the sign and zero restrictions has been obtained.

When only considering sign restrictions, Algorithm 1 collapses to the algorithm described in Rubio-Ramírez, Waggoner, and Zha (2010). This latter algorithm is much faster and, hence, we will use it when possible.

The key conceptual difference between Algorithm 1 and the algorithm in Rubio-Ramírez, Waggoner, and Zha (2010) is in Step 1. The set of structural parameters satisfying the zero restrictions is of measure zero in the set of all structural parameters. Nevertheless, the set of structural parameters satisfying the sign restrictions is of positive measure in the set of structural parameters satisfying the zero restrictions. Algorithm 1 exploits this intuition and takes draws from the posterior distribution of $\left(\mathbf{A}_{0}, \mathbf{A}_{+}\right)$that are conditional on the zero restrictions, checking the sign restrictions in Step 2.

The implications of this discussion are twofold. First, although we impose some zero restrictions, we still set identify the model - that is, we identify a set of models that are coherent with both the sign and the zero restrictions on $\mathbf{A}_{\mathbf{0}}$. Second, the set of models identified imposing both the sign and zero restrictions are of measure zero in the set of models identified by imposing only the sign restrictions. This second implication will be useful in Section 3.3.1, where we compare our results to Uhlig (2005).

\subsection{Systematic Component of Monetary Policy}

Leeper, Sims, and Zha (1996); Leeper and Zha (2003); and Sims and Zha (2006a) emphasize that the identification of monetary policy shocks is equivalent to the identification of a monetary 
policy equation. That is, the identification of monetary policy shocks either requires or implies the specification of the systematic component of policy, or how policy usually reacts to economic conditions.

In order to characterize the systematic component of monetary policy, it is important to note that labeling a structural shock in the SVAR as the monetary policy shock is equivalent to specifying the same equation as the monetary policy equation. Without loss of generality, we label the first shock to be the monetary policy shock. Thus, the first equation of the SVAR,

$$
\mathbf{y}_{t}^{\prime} \mathbf{a}_{0,1}=\sum_{\ell=1}^{p} \mathbf{y}_{t-\ell}^{\prime} \mathbf{a}_{\ell, 1}+\varepsilon_{1 t} \quad \text { for } 1 \leq t \leq T,
$$

is the monetary policy equation, where $\varepsilon_{1 t}$ denotes the first entry of $\varepsilon_{t}, \mathbf{a}_{\ell, 1}$ denotes the first column

of $\mathbf{A}_{\ell}$ for $0 \leq \ell \leq p$, and $a_{\ell, i j}$ denotes the $(i, j)$ entry of $\mathbf{A}_{\ell}$ and describes the systematic component of monetary policy.

From equation (3), it is clear that restricting the systematic component of monetary policy is equivalent to restricting $\mathbf{a}_{\ell, 1}$ for $0 \leq \ell \leq p$. In our baseline identification scheme, to be described in Section 2.3, we only restrict the contemporaneous coefficients in $\mathbf{a}_{0,1}$. We do this because the SVAR studies that inspire our baseline identification only impose restrictions on $\mathbf{A}_{0}$. Imposing restrictions on lagged coefficients is more controversial, as it is harder to find consensus on their implementation. Nevertheless, exploiting the generality of our methodology, in Section 4 we will also consider some cases in which we restrict lagged coefficients.

\subsection{The Baseline Identification}

Following the literature we use data on output, $y_{t}$; prices, $p_{t}$; commodity prices, $p_{c, t}$; total reserves, $t r_{t}$; nonborrowed reserves, $n b r_{t}$; and the federal funds rate, $r_{t}$. This vector of endogenous variables is standard in the literature and has been used by, among others, Christiano, Eichenbaum, and Evans (1996); Bernanke and Mihov (1998); and Uhlig (2005). Details about the exact definition of each of the six variables, together with the reduced-form VAR model specification, are provided in Section 3.1 .

Our baseline identification scheme is motivated by Christiano, Eichenbaum, and Evans (1996), 
whose monetary policy equation makes the following assumption:

Restriction 1. The federal funds rate is the monetary policy instrument and it only reacts contemporaneously to output and prices.

Restriction 1 comprises two parts. The first, that the federal funds rate is the policy instrument, is supported by empirical and anecdotal evidence. Except for a short period between October 1979 and October 1982 when the Federal Reserve explicitly targeted nonborrowed reserves, monetary policy in the U.S. since 1965 can be characterized by a direct or indirect federal funds rate targeting regime (see Bernanke and Blinder (1992); Romer and Romer (2004); and Chappell Jr, McGregor, and Vermilyea (2005) for details). Sims and Zha (2006b) also provide support for this view in their finding that the federal funds rate was the policy instrument for most of their sample, which runs from 1959 to 2003. Even so, they also suggest that one should be careful when applying Taylor formalism to interpret specific historical periods; for example, as in Bernanke and Blinder (1992), they find that policy behavior was better characterized by targeting nonborrowed reserves in the first three years of Paul Volcker's tenure as Chairman of the Federal Reserve from October 1979 to October 1982, as well as in the first years of Arthur Burns' tenure as Chairman of the Fed in the early 1970s. With these exceptions in mind, one could conclude that the Fed has used the federal funds rate as its monetary policy instrument almost continuously since 1965, although the federal funds rate has only formally been the Federal Reserve's policy instrument since 1997.5

The second, is that the federal funds rate does not react to changes in reserves. Bernanke and Blinder (1992) and Christiano, Eichenbaum, and Evans (1996) include reserves in their specifications because in the mid-1990s they were viewed as valid instruments for characterizing the conduct of monetary policy. Nevertheless, in these papers, when the federal funds rate is the monetary instrument, reserves do not enter the monetary equation. Restriction 1 is also consistent with Romer and Romer (2004), as reserve aggregates are not included in their regressions.

We complement Restriction 1 with qualitative restrictions on the response of the federal funds rate to economic conditions, which we summarize as follows.

5 Christiano, Eichenbaum, and Evans $(\sqrt{1996})$ also study a monetary policy equation where nonborrowed reserves are the policy instrument. We do not explore this specification because the analysis in Christiano, Eichenbaum, and Evans (1996) is not robust to extending the sample beyond 1995. This is consistent with the view that nonborrowed reserves were used as an explicit policy instrument only in the early 1980s. Nonetheless, we can modify Restriction 1 to require that nonborrowed reserves is the policy instrument. 
Restriction 2. The contemporaneous reaction of the federal funds rate to output and the GDP deflator is nonnegative.

Restriction 2 restricts the sign of the response of the federal funds rate to output and the GDP deflator while keeping the reaction to commodity prices unrestricted. Restriction 2 captures our basic understanding of how the Federal Reserve reacts to changes in the economic environment to fulfill its objectives of stable prices and maximum employment, as stated in the Federal Reserve Act. Restriction 2 is also supported by the literature. For example, the inflation and output (gap or growth) coefficients of Taylor-type rules are positive. Furthermore, Restriction 2 is also consistent with Romer and Romer (2004) ${ }^{6}$ Finally, as we show in the next section, Restriction 2 is also implied by Christiano, Eichenbaum, and Evans (1996).

We see the set of monetary policy equations that are consistent with Restriction 1 and 2 as the largest set of equations describing the historical conduct of U.S. monetary policy by the Federal Reserve. Importantly, we stress that Restrictions 1 and 2 are sign and zero restrictions on the coefficients of the monetary policy equation and that they do not impose restrictions on the IRFs of any variables to the monetary policy shocks. Hence, we remain agnostic about the output response to the monetary policy shock. A key departure from Christiano, Eichenbaum, and Evans (1996) is that we set and partially identify the model. Thus, as in Uhlig (2005), we allow for a set of models to be compatible with the sign and zero restrictions rather than a single one.

Since our identification concentrates on the contemporaneous coefficients, we can rewrite equation (3), abstracting from lag variables, as

$$
r_{t}=\psi_{y} y_{t}+\psi_{p} p_{t}+\psi_{p_{c}} p_{c, t}+\psi_{t r} t_{t}+\psi_{n b r} n b r_{t}+a_{0,61}^{-1} \varepsilon_{1, t}
$$

where $\psi_{y}=a_{0,61}^{-1} a_{0,11}, \psi_{p}=a_{0,61}^{-1} a_{0,21}, \psi_{p_{c}}=a_{0,61}^{-1} a_{0,31}, \psi_{t r}=a_{0,61}^{-1} a_{0,41}$, and $\left.\psi_{n b r}=a_{0,61}^{-1} a_{0,51}\right]^{7}$ Equipped with this representation of the monetary policy equation, we describe Restrictions 1 and 2 as follows.

\footnotetext{
${ }^{6}$ It is the case that both Taylor-type rules and Romer and Romer (2004) consider prices in first differences. As we will see below, our results are robust to this specification.

${ }^{7}$ From the subindices is easy to infer that the order of the variables in the reduced-form VAR model specification is $y_{t}, p_{t}, p_{c, t}, t r_{t}, n b r_{t}$, and $r_{t}$.
} 
Remark 1. Restriction 1 implies that $\psi_{t r}=\psi_{n b r}=0$, while Restriction 2 implies that $\psi_{y}, \psi_{p}>0$. At the same time, $\psi_{p_{c}}$ remains unrestricted.

In addition to Restrictions 1 and 2, we impose the likelihood-preserving (LP) normalization discussed in Waggoner and Zha (2003) ${ }^{8}$ We also restrict $a_{0,61}>0$ to ensure that we satisfy the regularity conditions for $f\left(\mathbf{A}_{0}, \mathbf{A}_{+}\right)$specified in Arias, Rubio-Ramirez, and Waggoner (2014).

Let $s_{10}$, the number of sign restrictions at horizon 0 , be 3 and $z_{10}$, the number of zero restrictions at horizon zero, be 2 . Restrictions 1, 2, and the restriction on $a_{0,61}$ are characterized by the following matrices:

$$
\begin{gathered}
f\left(\mathbf{A}_{0}, \mathbf{A}_{+}\right)=\mathbf{A}_{0} \\
\mathbf{S}_{1}=\left[\begin{array}{cccccc}
-1 & 0 & 0 & 0 & 0 & 0 \\
0 & -1 & 0 & 0 & 0 & 0 \\
0 & 0 & 0 & 0 & 0 & 1
\end{array}\right] \text { and } \mathbf{Z}_{1}=\left[\begin{array}{cccccc}
0 & 0 & 0 & 1 & 0 & 0 \\
0 & 0 & 0 & 0 & 1 & 0
\end{array}\right]
\end{gathered}
$$

Thus, our baseline identification scheme only restricts $\mathbf{A}_{0}$ and, in particular, its first column, $\mathbf{a}_{0,1}$.

\section{Results}

In this section, after discussing the data and the reduced-form VAR model specification, we describe the IRFs to a monetary policy shock obtained using our baseline identification scheme. We then discuss how and why our results differ from two existing SVAR studies linked to our approach. First, we relate our results to the work of Uhlig (2005). This is a natural comparison because while both approaches are agnostic, and both set and partially identify the model, we obtain very different responses of output to monetary policy shocks than Uhlig (2005) does. Second, we connect this paper to Christiano, Eichenbaum, and Evans (1996). This comparison is also natural not only because their paper motivates our Restriction 1, but also because they impose the questionable exclusion restrictions to which Uhlig (2005) refers.

\footnotetext{
${ }^{8}$ We also considered the sign of the IRF of the federal funds rate to a monetary policy shock as a normalization and the results to be reported are remarkably similar.
} 


\subsection{Dataset and Reduced-Form VAR Model Specification}

Our dataset contains monthly U.S. data for the following variables: real GDP, the GDP deflator, a commodity price index, total reserves, nonborrowed reserves, and the federal funds rate. The monthly time series for real GDP and the GDP deflator are constructed using interpolation, as in Bernanke and Mihov (1998) and Mönch and Uhlig (2005). Real GDP is interpolated using the industrial production index, while the GDP deflator is interpolated using the consumer price index and the producer price index. The commodity price index is from Global Financial Data and corresponds to monthly averages of daily data. The remaining variables are obtained from the St. Louis Fed website using the following mnemonics: BOGNONBR (nonborrowed reserves), CPIAUCSL (consumer price index), FEDFUNDS (the federal funds rate), GDPC1 (real GDP), GDPDEF (GDP deflator), INDPRO (industrial production), PPIFGS (producer price index), and TRARR (total reserves). All variables are seasonally adjusted except for the commodity price index and the federal funds rate.

To enhance comparability, we have reconstructed and updated Uhlig s (2005) dataset covering the 1965m1-2003m12 period 9 For the same reason, we have taken the details of the prior distribution and reduced-form VAR model specification described in Uhlig (2005). Specifically, the VAR includes $p=12$ lags and does not include any constant or deterministic term. We have repeated the analysis using an extended version of the monthly dataset running until $2007 \mathrm{~m} 12$, using data at quarterly frequency until 2007q4, and using several specifications of the prior distributions on the reduced-form parameters. Results reported in the following sections are robust to these different specifications and are available upon request. 10

\subsection{IRFs Using Our Baseline Identification}

Figure 1 plots the IRFs to an exogenous tightening of monetary policy identified by imposing Restrictions 1 and 2 - our baseline identification scheme. Throughout the paper, we normalize the

\footnotetext{
${ }^{9}$ We have crossed-checked our data (constructed using the vintage as of May 2014) with the reconstruction of Uhlig]s (2005) dataset done by RATS, https://estima.com/procs_perl/uhligjme2005.zip, and we obtain almost identical results despite the fact that the RATS dataset corresponds to a different vintage.

${ }^{10}$ We cut the sample in 2007 because starting in 2008 there are movements in reserves behavior of a different order of magnitude associated with the global financial crisis. Furthermore, the federal funds rate has been at the zero lower bound since November 2008, and our paper is concerned with the characterization of monetary policy in normal times.
} 
size of the shock to be one standard deviation. All results are based on 10,000 draws from the posterior distribution of the structural parameters. The shadowed area shows the point-wise (that is, period-by-period) 68 percent confidence bands, and the solid lines show the point-wise median IRFs.

Panel $\mathrm{F}$ shows that a one standard deviation monetary policy shock leads to an immediate increase in the federal funds rate of around 25 basis points. Output (Panel A) drops on impact and remains significantly negative for one year after the policy innovation. Output exhibits a small hump-shape in its response, reaching its lowest point six months after the shock. The median response of the GDP deflator (Panel B) is negative. While some models included in the identified set feature the price puzzle, our restrictions imply a substantial probability mass on models that have the GDP deflator falling after a monetary tightening. Following the decline in output and prices, the monetary authority loosens its stance shortly after the intervention, in line with our assumptions on the systematic component of monetary policy.

The impact response of total reserves (Panel D) is zero, turning positive thereafter. The impact response of nonborrowed reserves (Panel E) is negative, and also turns positive thereafter. The latter response does not feature a liquidity puzzle, as nonborrowed reserves drop when the federal funds rate is positive and increase only when the economy is in recession and the monetary stance loosens.

All told, we have shown that simply imposing some discipline on the systematic component of monetary policy is enough to recover the conventional effects of monetary policy reported in Bernanke and Blinder (1992); Christiano, Eichenbaum, and Evans (1996); Leeper, Sims, and Zha (1996); and Bernanke and Mihov (1998). Hence, contrary to Uhlig s (2005) claims, an agnostic identification scheme can be consistent with the consensus without the need of imposing any questionable exclusion restrictions on the responses of output. We also highlight that we do not need to restrict the responses of prices to eliminate the price puzzle.

\subsection{Relationship with the Existing Literature}

In this section, we first compare the results reported in Section 3.2 to the ones reported in Uhlig (2005). We then compare our results with those obtained by imposing a Cholesky identification 

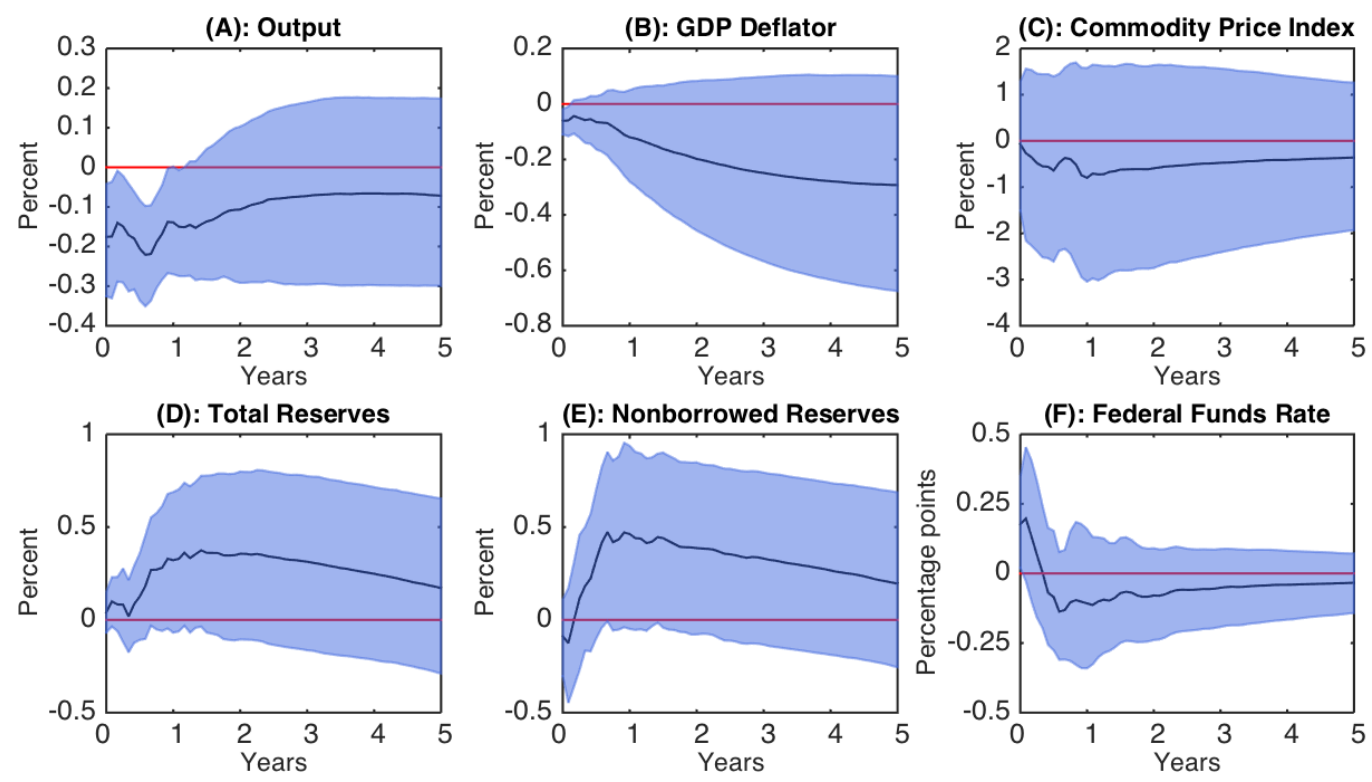

Figure 1: IRFs to a Monetary Policy Shock Identified Using Restrictions 1 and 2

scheme as in Christiano, Eichenbaum, and Evans (1996).

\subsubsection{Sign Restrictions on IRFs}

We now contrast our findings with Uhlig (2005). When analyzing monetary policy, agnostic identification schemes inspired by Uhlig's (2005) work are commonly associated with the rejection of the conventional view on the effects of monetary policy shocks on output. Since our baseline identification scheme shows that one can be agnostic and support the conventional view that contractionary monetary policy shocks do have contractionary effects on output, this seems a logical comparison to make when examining where the differences come from.

Uhlig (2005) imposes the following restriction.

Restriction 3. A monetary policy shock leads to a negative response of the GDP deflator, commodity prices, and nonborrowed reserves, and to a positive response of the federal funds rate, all at horizons $t=0, \ldots, 5$.

Restriction 3 rules out the price puzzle (a positive response of the price level following a monetary contraction) and the liquidity puzzle (a positive response of monetary aggregates). Uhlig (2005) 
motivates this restriction as a way to rule out implausible price and reserve behaviors, so that the set of admissible SVARs does not include models that we would find uninteresting from a theoretical perspective. While our baseline identification scheme only restricts $\mathbf{A}_{\mathbf{0}}$, Restriction 3 restricts the IRFs - that is, non-linear functions of $\left(\mathbf{A}_{\mathbf{0}}, \mathbf{A}_{+}\right)$. To see that, let $s_{10}=4$ and $s_{1+}$ (the number of sign restrictions at horizons greater than 1) be 20 . We characterize Restriction 3 with the matrices described below:

$$
\begin{gathered}
f\left(\mathbf{A}_{0}, \mathbf{A}_{+}\right)=\left[\begin{array}{c}
\mathbf{L}_{0}\left(\mathbf{A}_{0}, \mathbf{A}_{+}\right) \\
\vdots \\
\mathbf{L}_{5}\left(\mathbf{A}_{0}, \mathbf{A}_{+}\right)
\end{array}\right], \mathbf{S}_{1}=\left[\begin{array}{cccc}
\mathbf{S}_{10} & \mathbf{0}_{m, n} & \ldots & \mathbf{0}_{m, n} \\
\mathbf{0}_{m, n} & \ddots & \ddots & \vdots \\
\vdots & \ddots & \ddots & \mathbf{0}_{m, n} \\
\mathbf{0}_{m, n} & \cdots & \mathbf{0}_{m, n} & \mathbf{S}_{15}
\end{array}\right] \text {, and } \\
\mathbf{S}_{1 t}=\left[\begin{array}{cccccc}
0 & -1 & 0 & 0 & 0 & 0 \\
0 & 0 & -1 & 0 & 0 & 0 \\
0 & 0 & 0 & 0 & -1 & 0 \\
0 & 0 & 0 & 0 & 0 & 1
\end{array}\right] \text { for } t=0, \ldots, 5, \text { where } m=4 \text { and } n=6 .
\end{gathered}
$$

The key features shared by Restrictions 1,2 , and 3 are that (i) they remain agnostic about the response of output after a monetary policy shock and (ii) they set and partially identify the models. To closely follow Uhlig (2005), we do not use the LP normalization in this case. In fact, whenever Restriction 3 is in place, we do not use the LP normalization.

In Figure 2, we plot the IRFs to an exogenous tightening of monetary policy identified by imposing Restriction 3. This figure replicates Figure 6 in Uhlig (2005). The median response of output, reported in Panel A, is positive. In addition, there is evidence that in the short run the 68 percent confidence bands do not contain zero. Panels $\mathrm{B}$ and $\mathrm{C}$ show the responses of the GDP deflator and the commodity price index, respectively, which are restricted to be negative for six months to exclude the price puzzle. The responses of total reserves and nonborrowed reserves, reported in Panels D and E, are negative in the short run. The reduction in nonborrowed reserves is 
more significant because the response of this variable is restricted to be negative for six months to exclude the liquidity puzzle. Finally, the response of the federal funds rate, reported in Panel F, is restricted to be positive for the first six months, and it becomes negative 18 months after the shock.
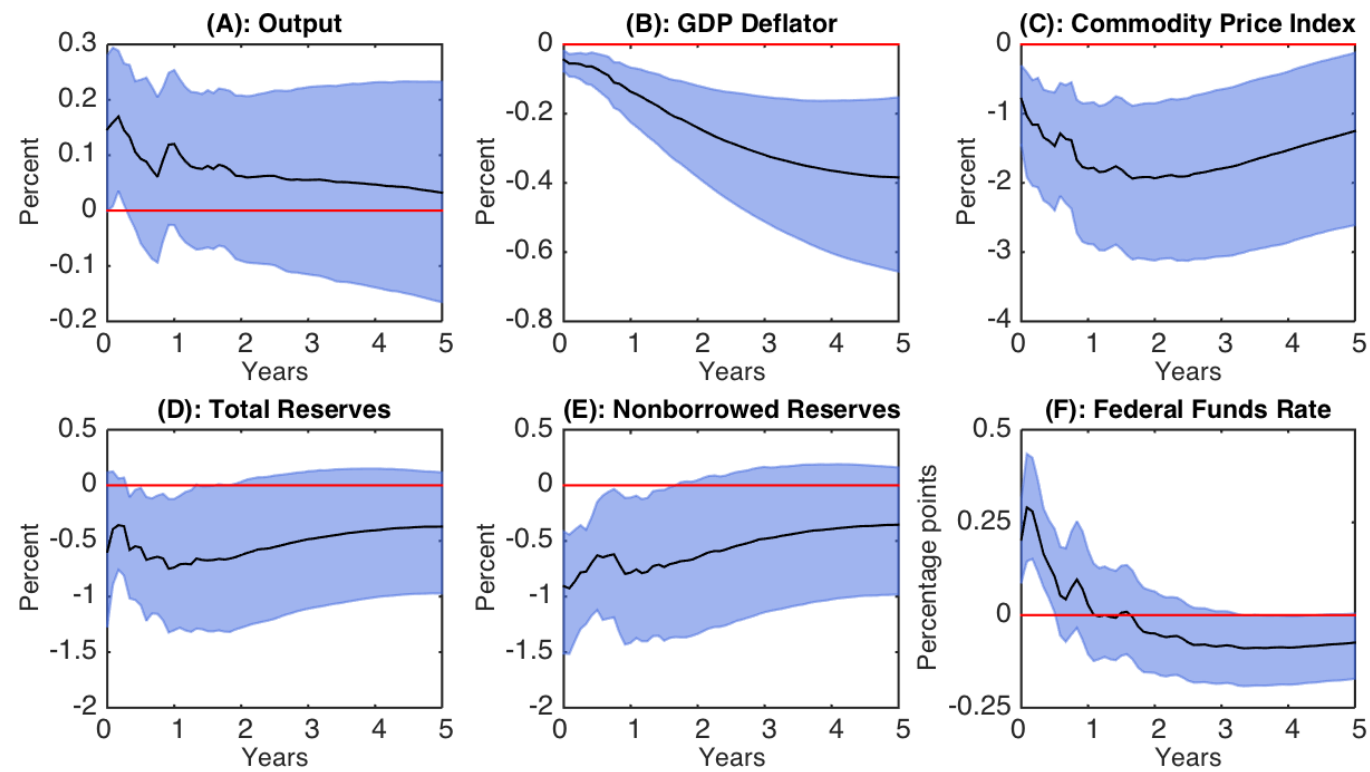

Figure 2: IRFs to a Monetary Policy Shock Identified Using Restriction 3

The main result shown in Figure 2 is the lack of support for the contractionary effects on output of an exogenous increase in the federal funds rate. A natural question to ask is: What is the systematic component of monetary policy associated with the set of monetary policy shocks identified by Restriction 3? Table 1 responds to this question.

\begin{tabular}{|l|c|c|c|c|c|}
\hline & $\mathrm{P}\left(\psi_{t r} \neq 0\right)$ & $\mathrm{P}\left(\psi_{n b r} \neq 0\right)$ & $\mathrm{P}\left(\psi_{y}<0\right)$ & $\mathrm{P}\left(\psi_{p}<0\right)$ & $\mathrm{P}\left(\psi_{y}<0 \cup \psi_{p}<0\right)$ \\
\hline Restriction 3 & 1.00 & 1.00 & 0.66 & 0.16 & 0.79 \\
\hline Restrictions 1 1 and 3 & 0.00 & 0.00 & 0.84 & 0.01 & 0.84 \\
\hline
\end{tabular}

Table 1: Probability of Violating Restrictions on the Systematic Component of Monetary Policy

The first row in Table 1 describes the systematic component of monetary policy that is implied by the monetary policy shocks identified in Uhlig (2005). By construction, the set of models that satisfy Restriction 3 implies $\psi_{t r} \neq 0$ and $\psi_{n b r} \neq 0$, thus violating Restriction 1 , It is because of 
this that, if we only impose Restriction 3 , we obtain that $P\left(\psi_{t r} \neq 0\right)=P\left(\psi_{n b r} \neq 0\right)=1$. The probability of drawing a negative coefficient on output and the GDP deflator is 0.66 and 0.16, respectively, and the probability of violating Restriction 2 is 0.79 . This exercise shows that Uhlig]s (2005) identification scheme implies a counterfactual systematic component of monetary policy that violates both Restrictions 1 and 2, Following Leeper, Sims, and Zha (1996); Leeper and Zha (2003); and Sims and Zha (2006a), a corollary to the findings reported in the first row of Table 1 is that the shocks identified by Restriction 3 are not monetary policy shocks.
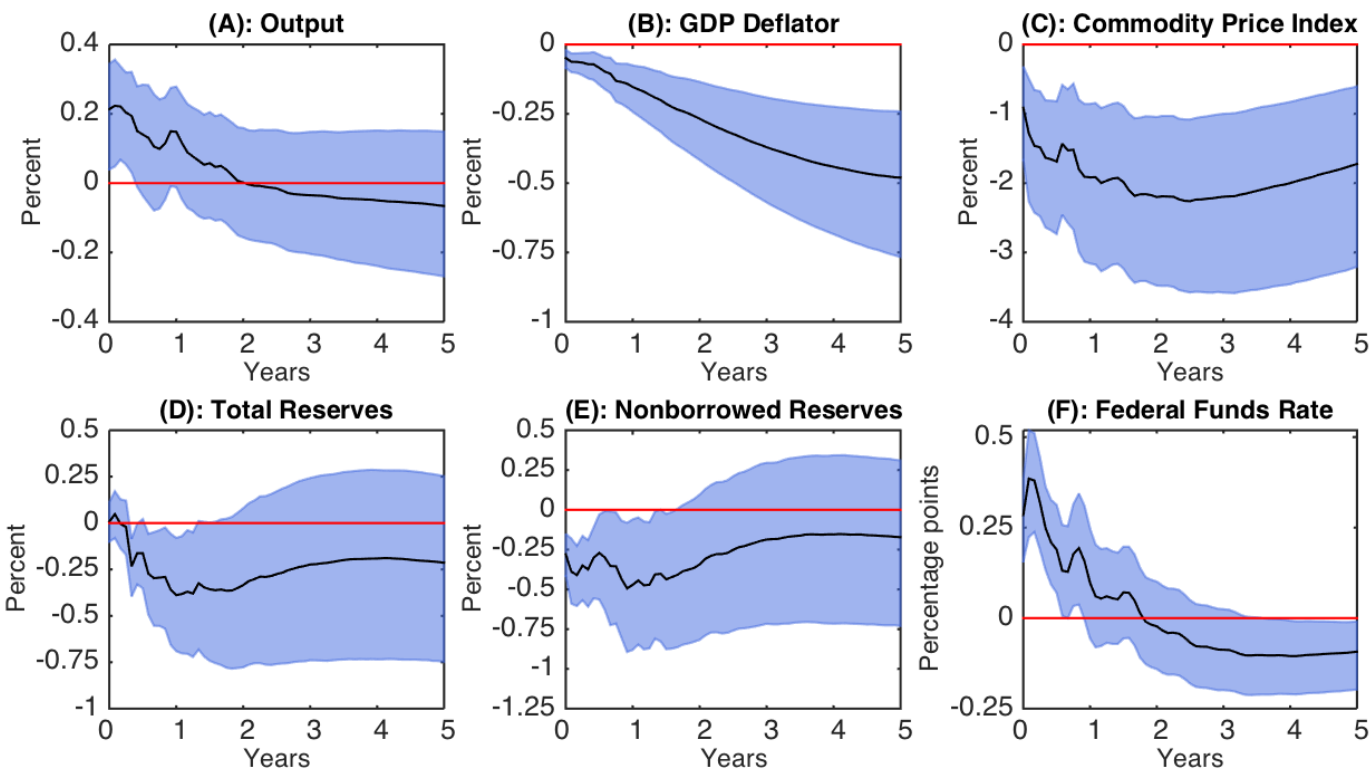

Figure 3: IRFs to a Monetary Policy Shock Identified Using Restrictions 1 and 3.

As explained in Section 2, unless we condition on the zero restrictions to draw the structural parameters, the set of models that satisfy Restriction 1 has measure zero. Hence, the set of models characterized by Restrictions 1 and 2 has measure zero in the set of models identified by Uhlig (2005). In other words, Restriction 1 is always violated in Uhlig (2005). To enhance the comparison across identification schemes, the second row in Table 1 describes the systematic component of monetary policy associated with Restrictions 1 and 3 . This means that we impose Uhlig s (2005) restrictions after conditioning on Restriction 1 (that is, that the federal funds rate does not react to reserves). The idea of this exercise is to give the monetary policy shocks identified by Uhlig (2005) a better chance of producing a systematic component of monetary policy that is not counterfactual. 
As the second row in Table 1 shows, the probability of drawing a negative $\psi_{y}$ is 0.84 , almost 20 percentage points higher than when we impose only Restriction 3 . The probability of drawing a negative $\psi_{p}$ drops to 0.05 , and the overall probability of violating Restriction 2 is 0.84 - very similar to the results reported in the first row. Hence, even under these more favorable circumstances, the shocks identified by Uhlig (2005) are not monetary policy shocks.
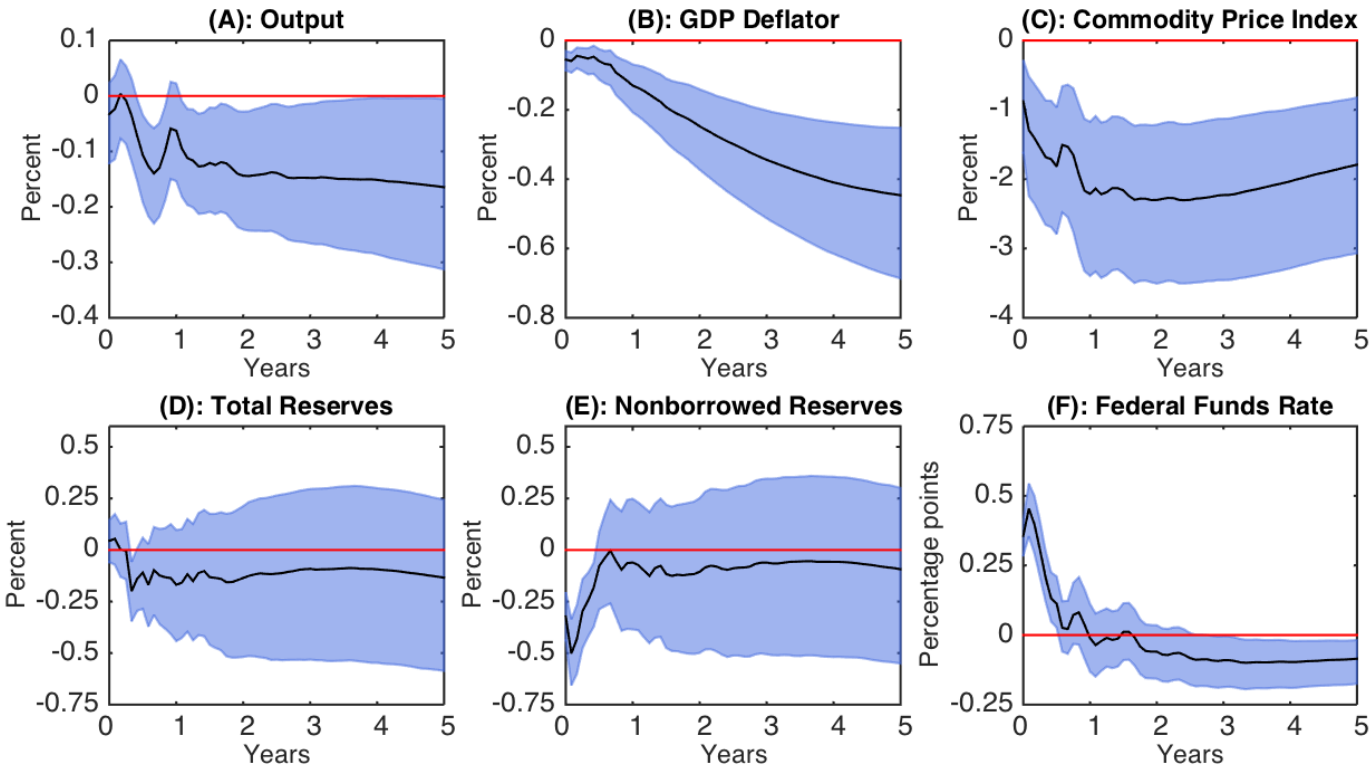

Figure 4: IRFs to a Monetary Policy Shock Identified Using Restrictions 1, 2, and 3

What are the consequences for the IRFs? Figure 3 plots the IRFs associated with Restrictions 1 and 3. As shown in Panel A, in comparison with the results reported in Figure 2, a higher probability of violating $\psi_{y}$ is associated with a more positive response of output to a monetary policy shock. The IRFs of the remaining variables are both qualitatively and quantitatively similar to those reported in Figure 2 .

Finally, Figure 4 presents results derived by imposing Restrictions 1, 2, and 3- combining Uhlig (2005) and our baseline identification scheme. We emphasize two results. First, the output response is negative and it builds up over time. Second, the contour of the federal funds rate is similar to that in Uhlig (2005): positive for one year and negative thereafter. But contrary to Uhlig (2005), we can rationalize this path with the systematic component of monetary policy, as the drop in the federal funds rate is the endogenous response of policy to the decline in output and prices. Figure 4 
reinforces the facts that our restrictions substantially shrink the set of models originally identified by Uhlig (2005) and that excluding models with counterfactual monetary policy equations suffices to generate a negative response of output and thereby recover the consensus.
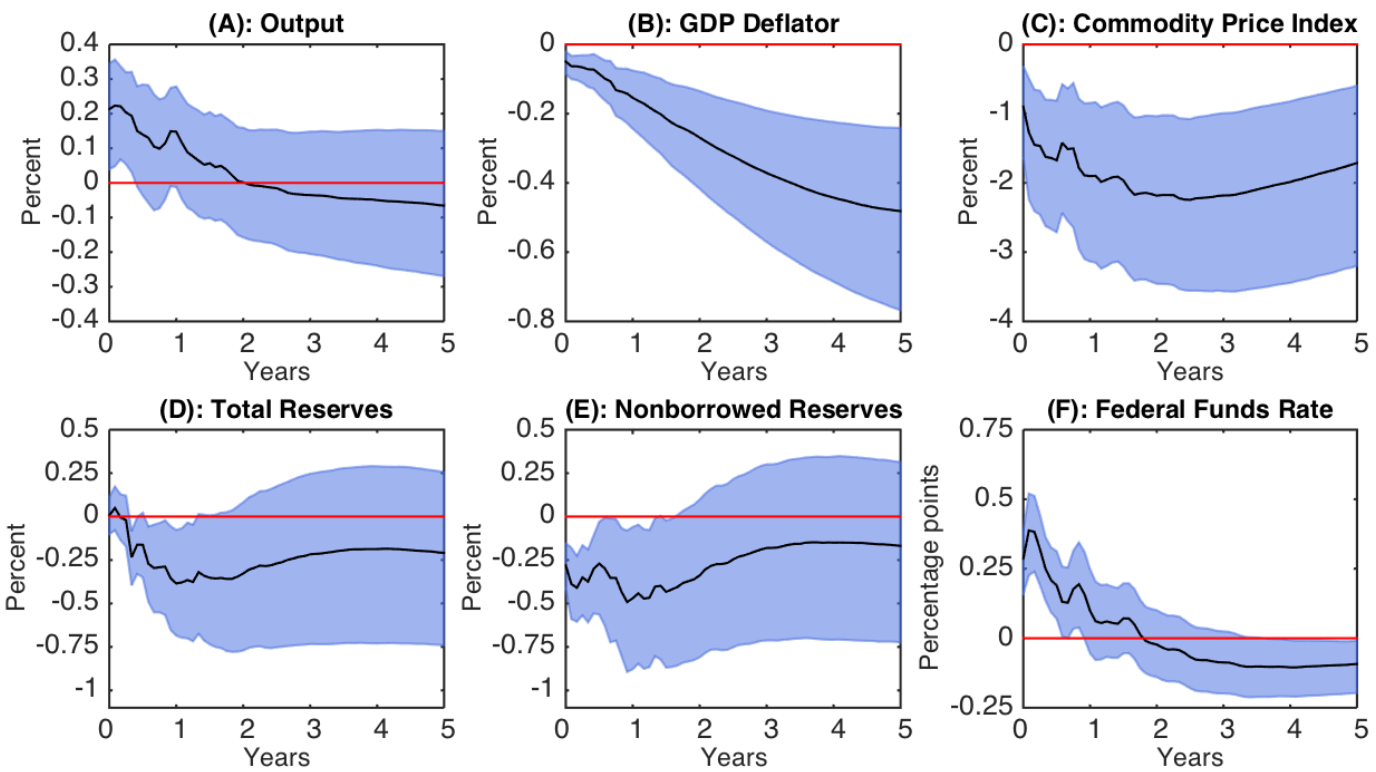

Figure 5: IRFs to a Monetary Policy Shock Identified Using Restrictions 1, 3, and $\psi_{p} \geq 0$

In order to understand which of the two sign restrictions within Restriction 2 is responsible for the change in the sign of the response of output to a monetary policy shock, we present Figures 5 and 6. Figure 5 presents the IRFs to a monetary policy shock identified using Restrictions 1, 3, and $\psi_{p} \geq 0$, while Figure 6 computes the same functions using Restrictions 1, 3, and $\psi_{y} \geq 0$. As is clear from Figures 5 and 6, the crucial restriction is $\psi_{y} \geq 0$. Even if we do not impose $\psi_{p} \geq 0$, output drops after a monetary policy shock.

All told, three findings emerge from this section. First, the sign restrictions on IRFs imposed in Uhlig (2005) imply a counterfactual systematic component of monetary policy and, hence, do not identify monetary policy shocks. Second, once the systematic behavior of monetary policy is restricted, the agnostic identification scheme in Uhlig (2005) is also consistent with the conventional effects of monetary policy. Third, the crucial restriction is $\psi_{y} \geq 0$. 

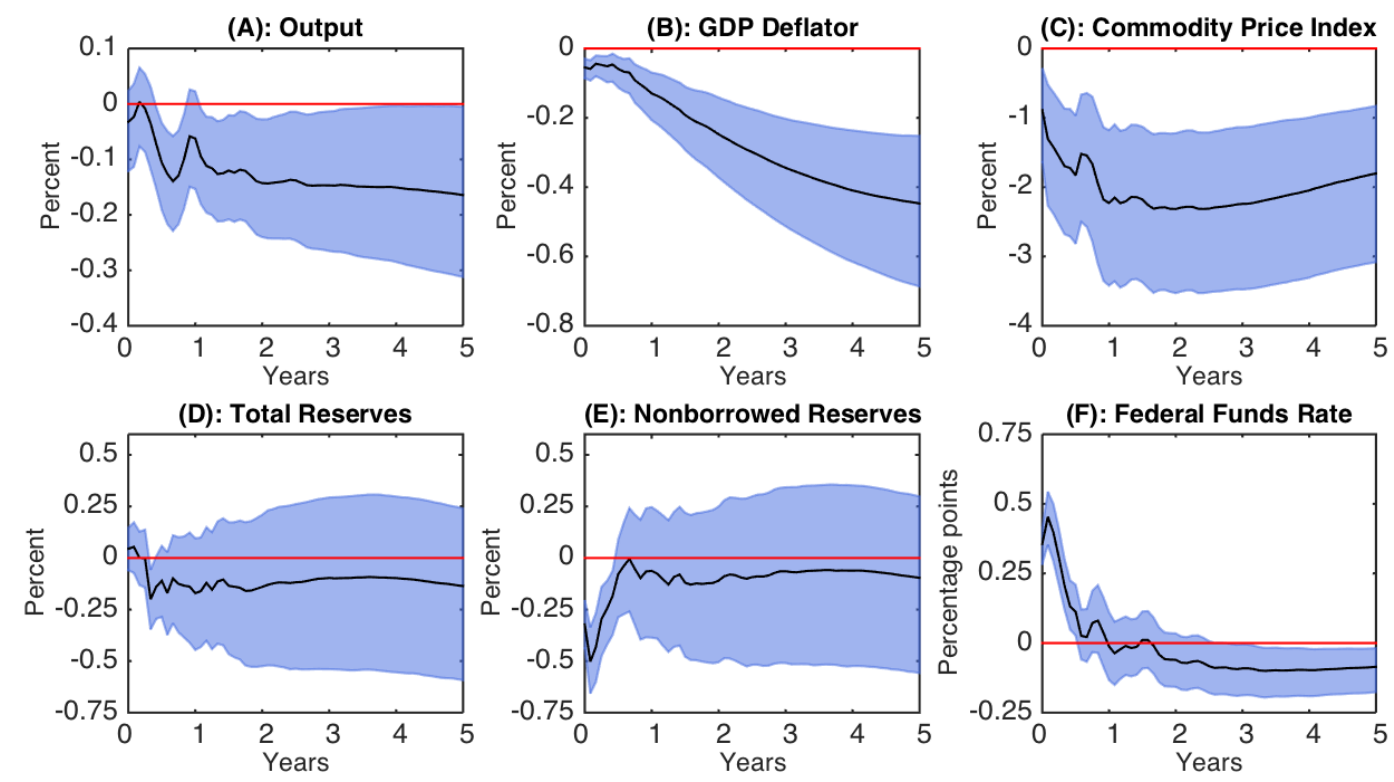

Figure 6: IRFs to a Monetary Policy Shock Identified Using Restrictions 1, 3 , and $\psi_{y} \geq 0$

\subsubsection{Cholesky Identification}

We now compare our baseline identification scheme and Uhlig (2005) with the Cholesky identification scheme used by Christiano, Eichenbaum, and Evans (1996). While Christiano, Eichenbaum, and Evans s (1996) identification motivates Restriction 1, it imposes the questionable exclusion restrictions on the behavior of output after a monetary policy shock to which Uhlig (2005) refers.

Let us begin by describing the ordering of the variables used in Christiano, Eichenbaum, and Evans (1996). The vector of endogenous variables is ordered as follows: output, prices, commodity prices, the federal funds rate, nonborrowed reserves, and total reserves. We do not use the LP normalization in this case because of the recursive structure. The federal funds rate is ordered fourth in the system. Thus, in line with Restriction 1, the federal funds rate does not react contemporaneously to changes in total and nonborrowed reserves.

Contrary to our baseline identification scheme and Uhlig (2005), Christiano, Eichenbaum, and Evans (1996) fully identify the model. The zero restrictions imposed on the remaining equations of the system imply that output and prices do not react contemporaneously to monetary policy shocks. Hence, Christiano, Eichenbaum, and Evans s (1996) analysis does not survive Uhlig s (2005) 
critique. It is also important to mention that a Cholesky identification scheme exactly identifies the model; that is, it identifies a single model, not a set of them. As a consequence, the results reported here only reflect reduced-form parameter uncertainty, while results reported in Sections 3.2 and 3.3 reflect both reduced-form parameter and model uncertainty.

\begin{tabular}{|c|c|c|c|}
\hline & $\mathrm{P}\left(\psi_{y}<0\right)$ & $\mathrm{P}\left(\psi_{p}<0\right)$ & $\mathrm{P}\left(\psi_{y}<0 \cup \psi_{p}<0\right)$ \\
\hline $\mathrm{CEE}(1996)$ & 0.00 & 0.10 & 0.10 \\
\hline
\end{tabular}

Table 2: Probability of Violating Zero and Sign Restrictions

Table 2 reports the probability that the Cholesky identification scheme violates the sign restrictions stated in Restriction 2. The probability of violating the sign restriction on $\psi_{y}$ is almost zero, while the probability of violating the sign restriction on $\psi_{p}$ is 0.10 . This means that, overall, the Cholesky identification scheme implies a systematic component of monetary policy that is broadly in line with our proposed baseline identification strategy. By construction, the Cholesky identification scheme always satisfies Restriction 1 .

Figure 7 shows the IRFs to a one standard deviation monetary policy shock identified by imposing the Cholesky identification scheme. The immediate response of the federal funds rate, reported in Panel D, is 50 basis points - twice as large as the response reported in Figure 1. This difference is due to the systematic component of monetary policy. Since output and prices do not react to the monetary policy shock on impact, there is no immediate endogenous response of the federal funds rate. Instead, under our baseline identification scheme, both output and prices drop contemporaneously. This drop leads to a contemporaneous endogenous response of the federal funds rate to the shock. This endogenous drop explains the smaller-impact increase of the federal funds rate after a monetary policy shock.

But, more importantly, output drops after the initial period. Compared with the results reported in Figure 1 for our baseline identification scheme, the output response is larger and more persistent. Moreover, the response of the GDP deflator features a substantial price puzzle. The latter can help to rationalize the persistent response of the federal funds rate despite the drop in output. Since the federal funds rate increases as prices increase, the monetary authority keeps a tight stance for 

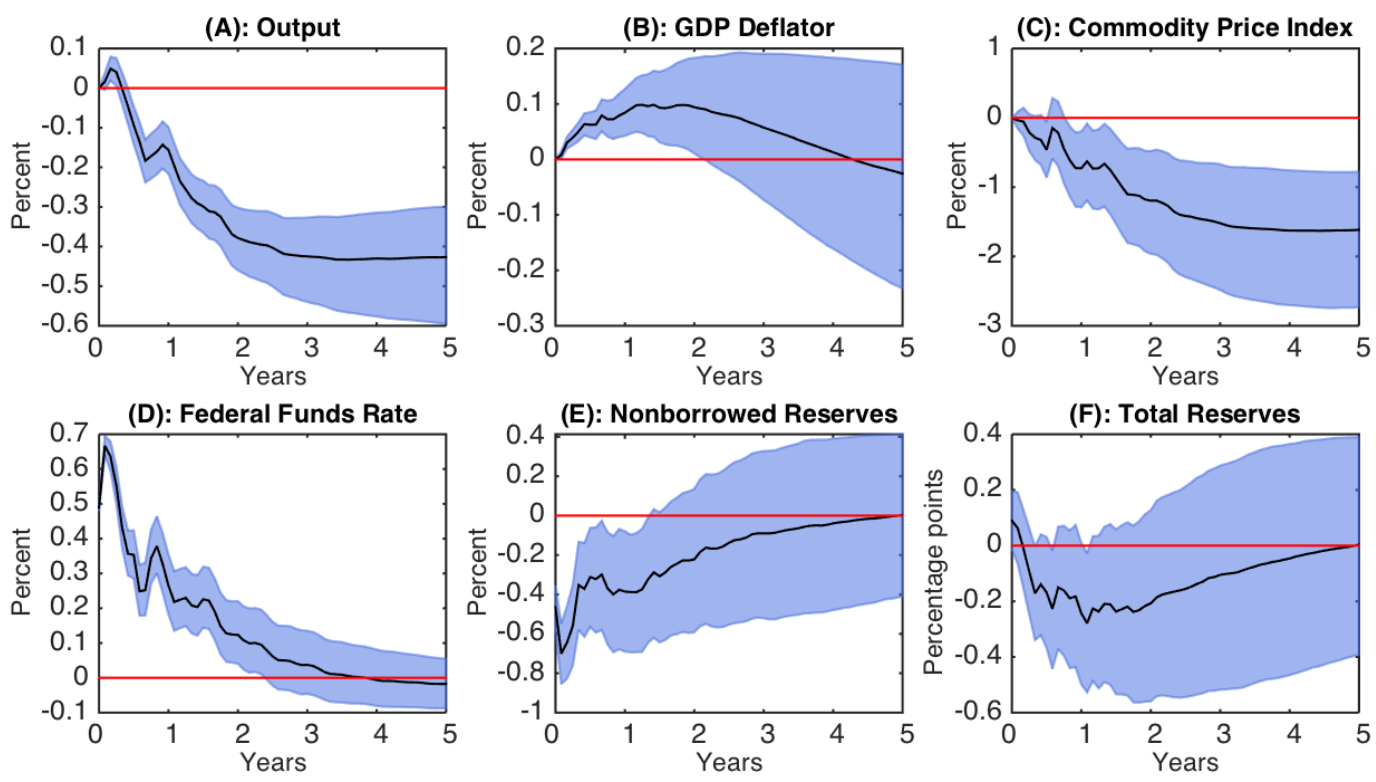

Figure 7: IRFs to a Monetary Policy Shock Identified Using CEE (1996) Cholesky Identification

longer because of the price puzzle.

The results reported in this section hint that the restrictions on the systematic component of monetary policy, and not the questionable exclusion restrictions, are crucial to generating a drop in output after a monetary policy shock. On the one hand, Uhlig (2005) does not impose the exclusion restrictions but rather obtains a counterfactual systematic component of monetary policy, invalidating his monetary policy shocks in the eyes of Leeper, Sims, and Zha (1996); Leeper and Zha (2003); and Sims and Zha (2006a). On the other hand, Christiano, Eichenbaum, and Evans (1996) impose exclusion restrictions that do not lead to a counterfactual systematic component of monetary policy but instead affect the size and shape of the IRF of output.

\section{Robustness}

To check the robustness of the results reported in Section 3.2 , we now explore three modifications to our baseline identification scheme. First, we specify two different restrictions on the reaction of the federal funds rate to commodity prices. Second, we impose a positive coefficient on the lagged federal funds rate. Third, we specify the monetary policy equation in first differences, in the spirit 
of Taylor-type monetary policy equations.
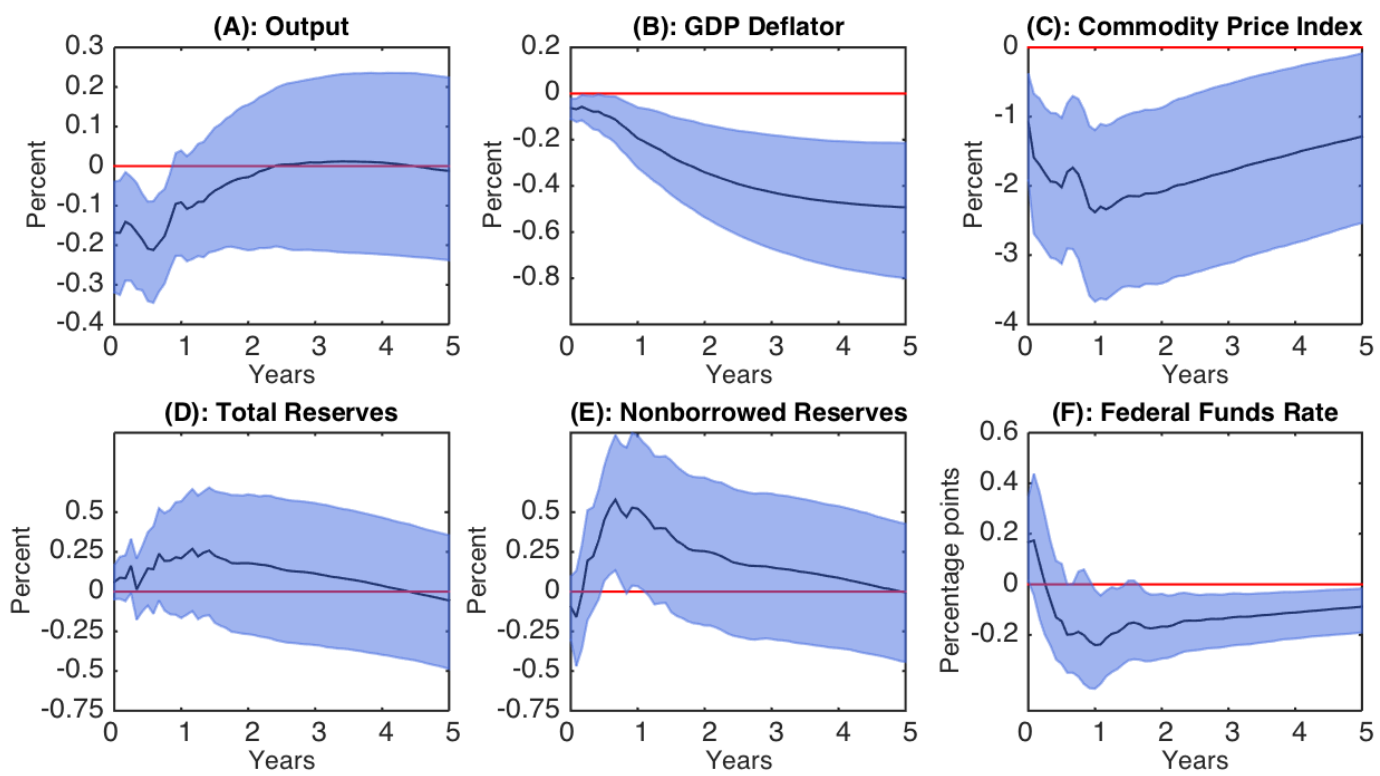

Figure 8: IRFs to a Monetary Policy Shock Identified Using Restrictions 1, 2, and $\psi_{p_{c}}>0$

\subsection{Commodity Prices}

As highlighted in Remark 1, our baseline identification scheme follows Christiano, Eichenbaum, and Evans (1996), by allowing the federal funds rate to respond to contemporaneous movements in commodity prices, but it does not impose any restriction on $\psi_{p_{c}}$. Bernanke, Gertler, Watson, Sims, and Friedman (1997) find evidence of monetary policy tightening following oil price shocks. But such policy reaction could be either a direct response to changes in commodity prices or an indirect reaction through changes in inflation. The former interpretation suggests imposing $\psi_{p_{c}}>0$, while the latter suggests imposing $\psi_{p_{c}}=0$. The zero restriction on $\psi_{p_{c}}$ is also consistent with standard specifications of the monetary policy equation in DSGE models, as well as with the empirical specification in Romer and Romer (2004). We now explore if either of these two interpretations of the evidence change the results reported in Figure 1.

Figure 8 plots the IRFs to a monetary policy shock when we add the restriction $\psi_{p_{c}}>0$ to our baseline identification scheme. With this additional restriction, the drop in commodity prices, shown in Panel C, becomes significant. The drop in the GDP deflator also becomes more significant. 
The stronger decline in prices, together with a drop in output of similar magnitude, implies a more pronounced medium-term loosening of the policy stance.

Figure 9 plots the IRFs to a monetary shock when we add the restriction $\psi_{p_{c}}=0$ to our baseline identification scheme. In this case, the additional restriction leads to a slightly more pronounced drop in output and prices - both in the GDP deflator and the commodity price index - and thereby to a more pronounced medium-term loosening of policy.
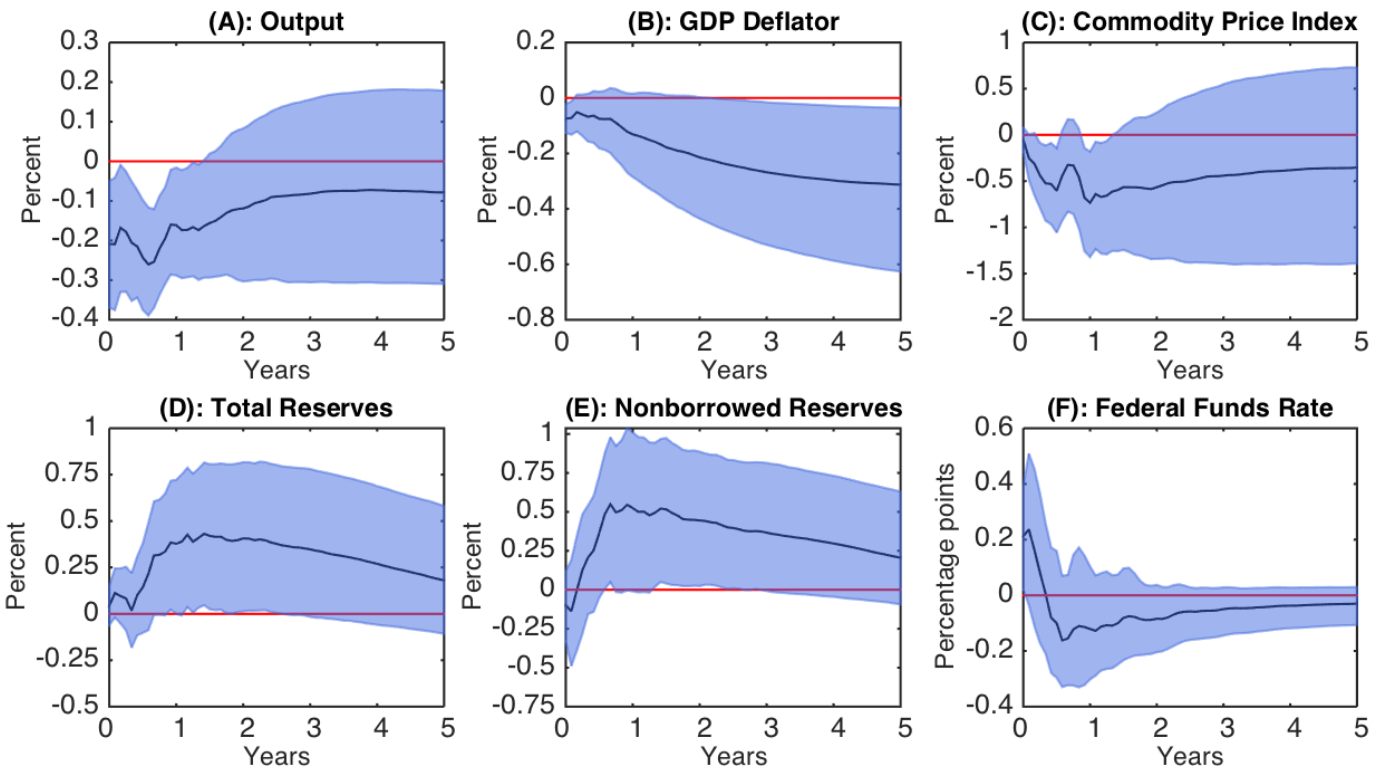

Figure 9: IRFs to a Monetary Policy Shock Identified Using Restrictions 1, 2, and $\psi_{p_{c}}=0$

From Figures 8 and 9 , we conclude that the results reported in Section 3.2 are robust to changes on the restrictions on $\psi_{p_{c}}$.

\subsection{Positive Coefficient on the Lagged Federal Funds Rate}

Many monetary policy equations considered in the DSGE literature include a coefficient for the lagged federal funds rate that is estimated to be positive. In order to consider this variant in our baseline identification, we restrict the coefficient associated with the lagged federal funds rate, $r_{t-1}$, to be positive. Abstracting from the remaining lags, we can rewrite equation (5) as

$$
r_{t}=\psi_{r} r_{t-1}+\psi_{y} y_{t}+\psi_{p} p_{t}+\psi_{p_{c}} p_{c, t}+\psi_{t r} t r_{t}+\psi_{n b r} n b r_{t}+a_{0,61}^{-1} \varepsilon_{1, t}
$$


where $\psi_{r}=a_{0,61}^{-1} a_{1,61}$.

Figure 10 plots the IRFs to a monetary policy shock when we add the restriction $\psi_{r}>0$ to our baseline identification scheme. The additional restriction marginally increases the persistence in the response of the federal funds rate and makes the response of output and prices more significant.

Results are very similar in variations of this experiment where we either restrict the coefficient on $r_{t-3}$ or $r_{t-6}$ to be positive instead of the coefficient on $r_{t-1}$, or where we restrict the three coefficients at the same time.
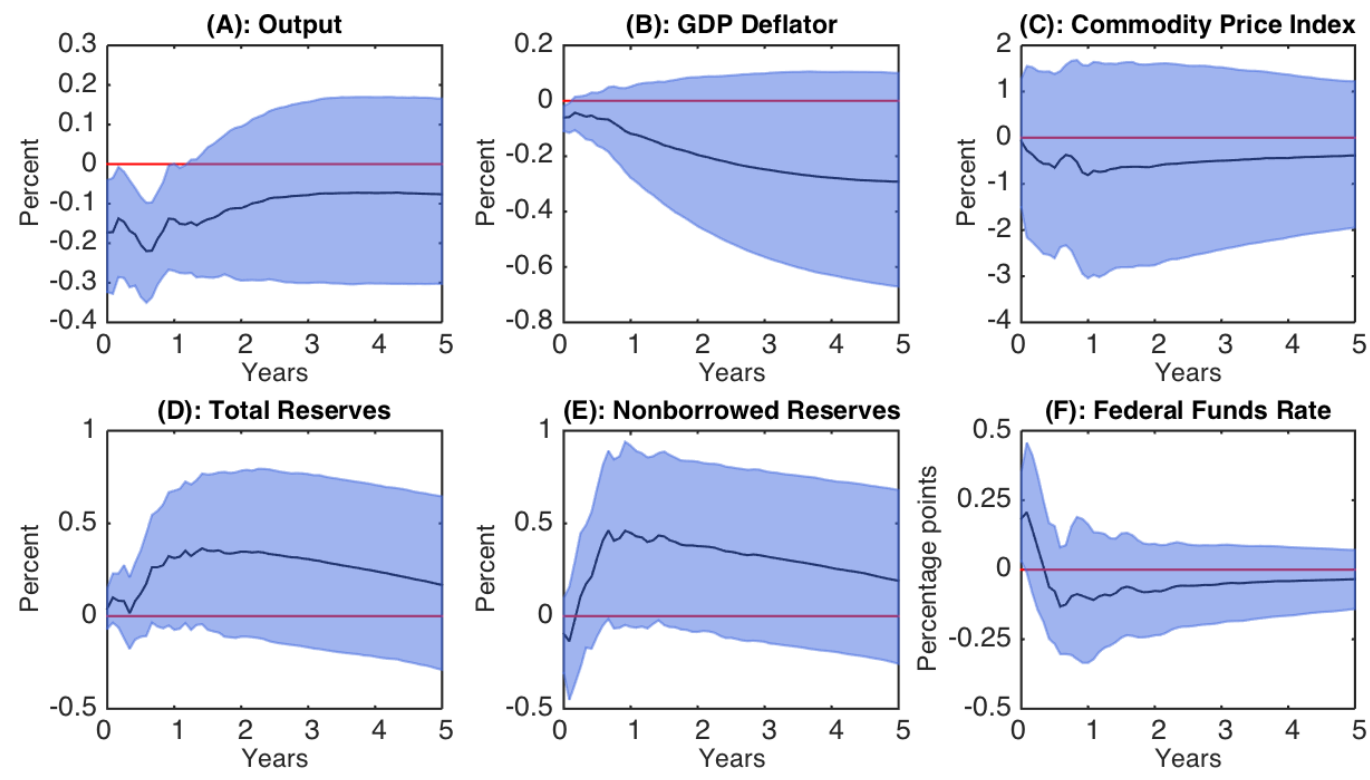

Figure 10: IRFs to a Monetary Policy Shock Identified Using Restrictions 1, 2, and $\psi_{r}>0$.

\subsection{Monetary Policy Equation in First Differences}

In our baseline identification scheme, the federal funds rate responds to output and price levels. But researchers, especially those working with DSGE models, often consider Taylor-type monetary policy equations in which the funds rate responds to inflation and some measures of economic activity, such as the output gap and/or GDP growth. To check the robustness of our results to this modification, we first re-estimate the reduced-form model in the first difference of all the variables but the federal funds rate, and then apply Restrictions 1 and 2 to the following monetary policy equation 11

\footnotetext{
${ }^{11}$ This specification also includes a constant.
} 

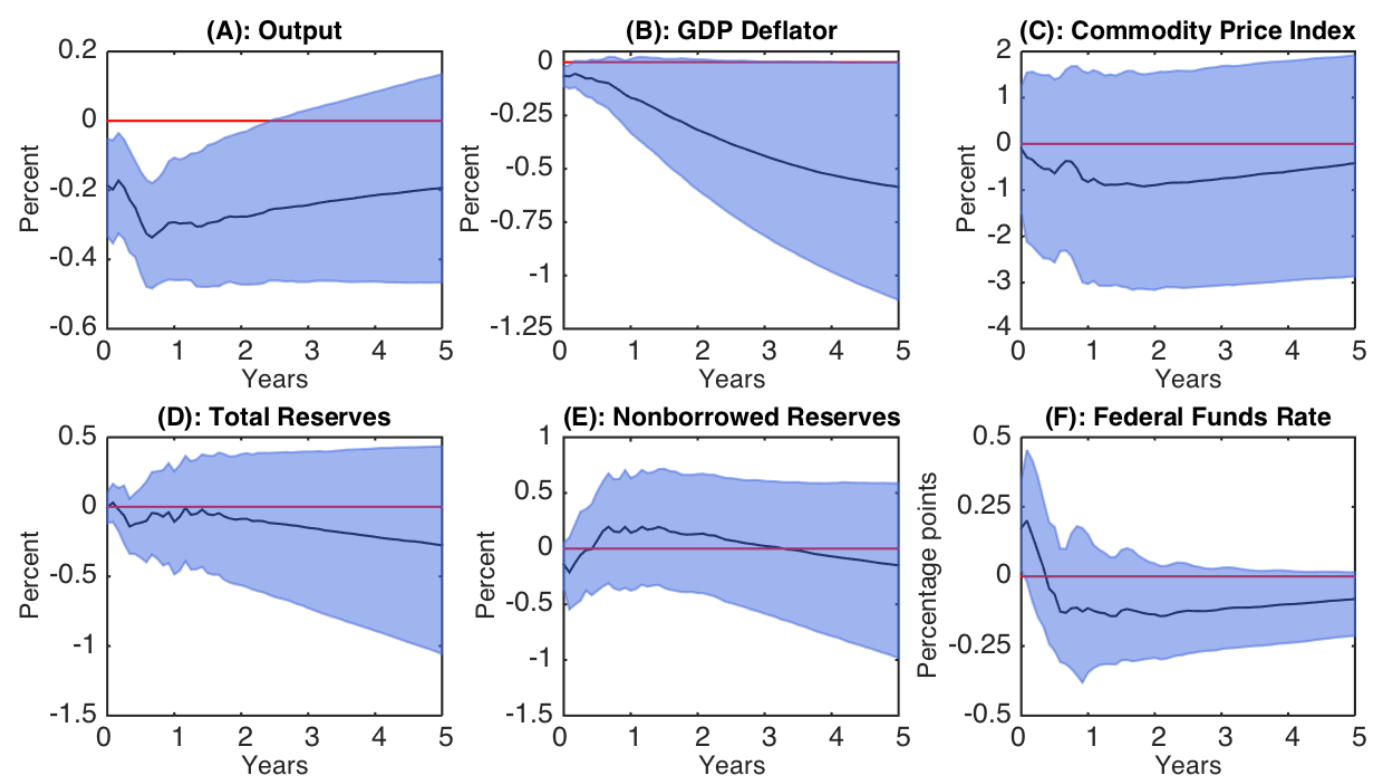

Figure 11: IRFs to a Monetary Policy Shock Identified Using Restrictions 1 and 2 .

Analogously to the monetary policy equation in levels, since our alternative identification also concentrates on the contemporaneous coefficients, we can abstract from the remaining lags and rewrite equation $(3)$ as

$$
r_{t}=\psi_{y} \Delta y_{t}+\psi_{p} \Delta p_{t}+\psi_{p_{c}} \Delta p_{c, t}+\psi_{t r} \Delta t r_{t}+\psi_{n b r} \Delta n b r_{t}+a_{0,61}^{-1} \varepsilon_{1, t}
$$

where all variables except for the federal funds rate are now in first differences 12

Figure 11 plots the responses to a one standard deviation monetary shock when Restrictions 1 and 2 are imposed on equation (6). Results are broadly consistent with those from the baseline specification. Even so, there are some differences: the drop in output is larger and more hump-shaped than in the baseline specification, and the negative response of the GDP deflator is also more pronounced. The sharper drop in output and prices leads to a more significant loosening of the monetary stance.

\footnotetext{
${ }^{12}$ Notice that we have also abstracted from the constant.
} 


\section{Money Rules}

In this section, we show that the results presented in Section 3 are not tied to the baseline identification scheme. We begin by describing our alternative identification scheme, which is motivated by the work of Leeper, Sims, and Zha (1996); Leeper and Zha (2003); and Sims and Zha (2006a b). These authors consider money rules as the monetary policy equation. Money rules have received wide attention in empirical studies of monetary policy, and they provide alternative descriptions of the systematic component of monetary policy.

We consider the money rule postulated in Leeper, Sims, and Zha (1996) and Sims and Zha $\left(2006 \mathrm{a}\right.$ b). In these rules, only the federal funds rate and money enter the monetary policy equation ${ }^{13}$ To model this rule, we follow Sims and Zha (2006b) and replace total reserves and nonborrowed reserves with money, $m_{t}$, as measured by M2 ${ }^{14}$ Except for the use of money instead of two measures of reserves, the dataset and the reduced-form VAR model are identical to those described in Section 3.1 .

We specify the following two restrictions that are consistent with the money rule.

Restriction 4. The federal funds rate is the monetary policy instrument and it only reacts contemporaneously to money.

Restriction 5. The contemporaneous reaction of the federal funds rate to money is nonnegative.

As in the case of the baseline identification scheme, we restrict the behavior of the monetary policy equation only using sign and zero restrictions, while leaving the remaining equations unrestricted. Again, two implications of this are that, we set and partially identify the model, and that we remain agnostic about the response of output to a monetary policy shock, since no restriction is placed on such a response.

We rewrite the monetary policy equation, concentrating on the contemporaneous coefficients, as

$$
r_{t}=\psi_{y} y_{t}+\psi_{p} p_{t}+\psi_{p_{c}} p_{c, t}+\psi_{m} m_{t}+a_{0,51}^{-1} \varepsilon_{1, t}
$$

\footnotetext{
${ }^{13}$ In Subsection 5.3 we implement Leeper and Zha $s$ (2003) version of this rule where the federal funds rate is also assumed to respond to commodity prices.

${ }^{14}$ We use seasonally adjusted monthly data on M2 money supply (M2SL) from the H.6 Money Supply Measures of the Board of Governors of the Federal Reserve System, downloaded from the Federal Reserve Bank of Saint Louis.
} 
where $\psi_{y}=a_{0,51}^{-1} a_{0,11}, \psi_{p}=a_{0,51}^{-1} a_{0,21}, \psi_{p_{c}}=a_{0,51}^{-1} a_{0,31}$, and $\psi_{m}=a_{0,51}^{-1} a_{0,41}{ }^{15}$ Equipped with this representation of the monetary policy equation, we summarize Restrictions 4 and 5 as follows.

Remark 2. Restriction 4 implies that $\psi_{y}=\psi_{p}=\psi_{p_{c}}=0$, while Restriction 5 implies that $\psi_{m} \geq 0$.

In addition to Restrictions 4 and 5, we also impose the LP normalization discussed in Waggoner and Zha (2003) ${ }^{16}$ And we restrict $a_{0,51}>0$ to ensure that we satisfy the regularity conditions for $f\left(\mathbf{A}_{0}, \mathbf{A}_{+}\right)$specified in Arias, Rubio-Ramirez, and Waggoner (2014).

Note also that under Restriction 4, the monetary equation (7) becomes

$$
r_{t}=\psi_{m} m_{t}+a_{0,51}^{-1} \varepsilon_{1, t}
$$

This equation has three possible interpretations. The first, which is consistent with how we specify equation (8), is that the federal funds rate responds to changes in the money supply. The second interpretation is that the money supply adjusts to changes in the federal funds rate. This interpretation is consistent with Sims and Zha $/$ s (2006b) view of how monetary policy was conducted between 1979 and 1982. A third interpretation is simply that both the federal funds rate and the money supply respond to Fed actions, and that both indicators are important in describing the effects of monetary policy on the economy. This third interpretation is consistent with Belongia and Ireland (2014) 17

Restrictions 4 and 5 and the restriction on $a_{0,51}$ are characterized by the following matrices:

$$
\begin{gathered}
f\left(\mathbf{A}_{0}, \mathbf{A}_{+}\right)=\mathbf{A}_{0} \\
\mathbf{S}_{1}=\left[\begin{array}{ccccc}
0 & -1 & 0 & 0 & 0 \\
0 & 0 & -1 & 0 & 0 \\
0 & 0 & 0 & -1 & 0 \\
0 & 0 & 0 & 0 & 1
\end{array}\right] \text { and } \mathbf{Z}_{1}=\left[\begin{array}{ccccc}
1 & 0 & 0 & 0 & 0 \\
0 & 1 & 0 & 0 & 0 \\
0 & 0 & 1 & 0 & 0
\end{array}\right] .
\end{gathered}
$$

\footnotetext{
${ }^{15}$ From the subindices it is easy to see that the order of the variables in the reduced-form VAR model specification are $y_{t}, p_{t}, p_{c, t}, m_{t}$, and $r_{t}$.

${ }^{16}$ We also considered the sign of the IRF of the federal funds rate to a monetary policy shock as a normalization and the results are remarkably similar.

${ }^{17}$ We have decided to follow the first interpretation. We could have written equation (8) consistently with either of the two other interpretations, but the restriction to ensure that we satisfy the regularity conditions would have been different.
} 

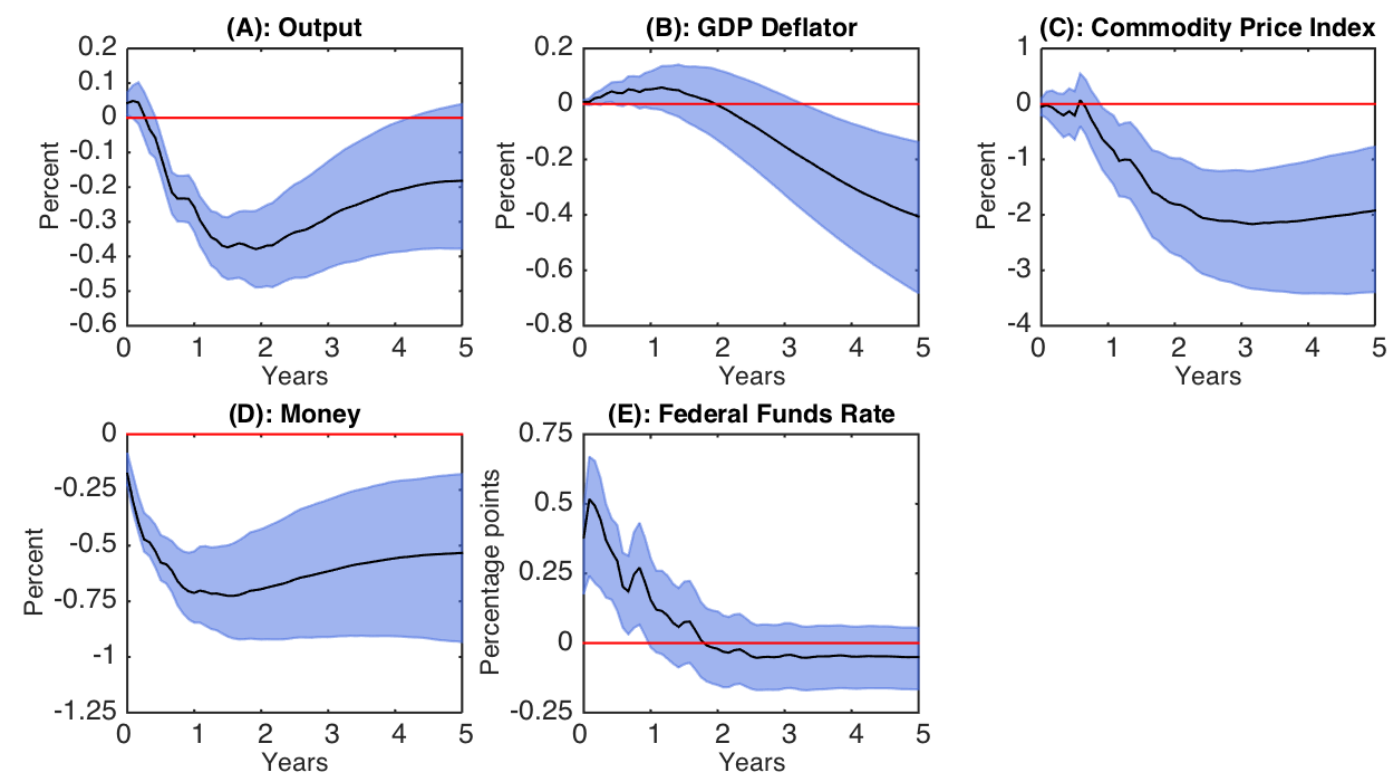

Figure 12: IRFs to a Monetary Policy Shock Identified Using Restrictions 4 and 5

\subsection{IRFs Using Our Alternative Identification}

In Figure 12, we plot the IRFs identified by imposing only Restrictions 4 and 5 - that is, our alternative identification scheme. Qualitatively, IRFs are similar to those plotted in Figure 1. The response of output is stronger and more hump-shaped than in Figure 1, with output returning to its pre-shock level within five years. The output response is more precisely estimated than in the baseline case, which is in line with the evidence that M2 helps forecast output in VARs that include the federal funds rate (see Belongia and Ireland (2014)). Leeper, Sims, and Zha (1996) also document that a VAR specification with M2 generates a strong decline in output. The response of the GDP deflator shows a more pronounced price puzzle than in Figure 1. The response of the federal funds rate is more persistent, with the stance tightening for the first 18 months and returning to its pre-shock level thereafter.

Since output drops after a monetary policy shock, it is the case that our alternative identification scheme also recovers the consensus. 

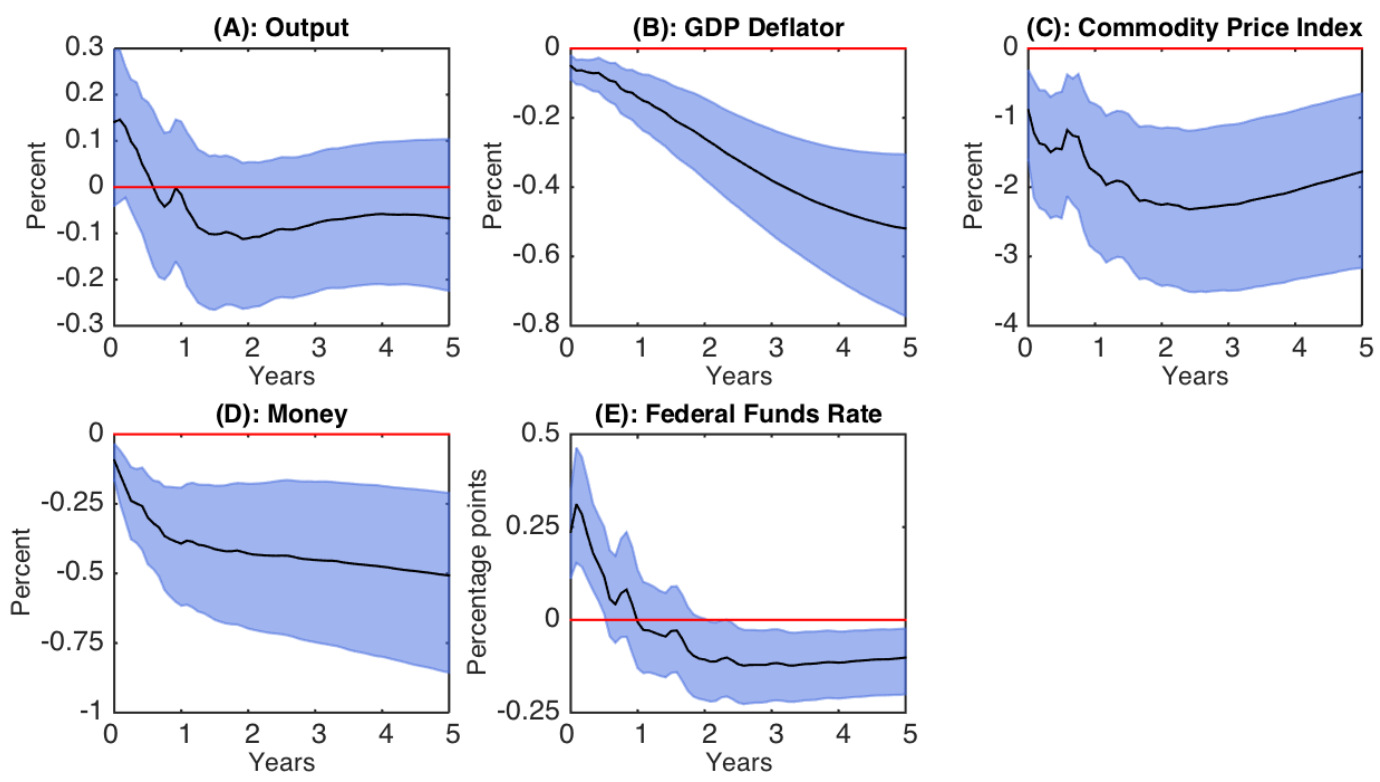

Figure 13: IRFs to a Monetary Policy Shock Identified Using Restriction 6

\subsection{Sign Restrictions on IRFs}

From Figures 1 and 12 one could easily conclude that as long as we follow Leeper, Sims, and Zha (1996) and Sims and Zha (2006a b) in restricting the systematic component of monetary policy, the consensus is recovered. But before concluding this, we need to check that we can replicate the main findings in Uhlig (2005) using the new reduced-form specification with five variables and money. It could be the case that the swapping of reserves for money is enough to generate a decline in output.

To implement Uhlig s 2005) agnostic identification scheme in the new reduced-form specification, we replace the sign restrictions on nonborrowed reserves with sign restrictions on money.

Restriction 6. A monetary policy shock leads to a negative response of the GDP deflator, commodity prices, and money, and to a positive response of the federal funds rate, all at horizons $t=0, \ldots, 5$.

As was the case with Restriction 3 , Restriction 6 rules out the price and liquidity puzzles and implies non-linear restrictions on $\left(\mathbf{A}_{\mathbf{0}}, \mathbf{A}_{+}\right)$, while remaining agnostic about the response of output after an increase in the federal funds rate. It is also the case that set and partially identifies the model. We omit the necessary matrices to characterize Restriction 6 because they follow trivially from those described in Section 3.3.1. As before, any time we use Restriction 6 we do not use the 


\section{LP normalization.}

We plot the resulting IRFs in Figure 13, As in Uhlig s (2005) specification with reserves instead of money, an increase in the federal funds rate leads to an increase in output. The output response becomes negative after about six months, but zero is always included in the 68 percent credible set. Therefore, there is no evidence that negative monetary policy shocks are contractionary when Restriction 6 is used to identify them: Uhlig s (2005) results survive the swap of reserves for money. Therefore, results reported in Figure 12 are not driven by the fact that we use money instead of reserves but instead by the restrictions on the systematic component of monetary policy.

To further understand the relationship between identification schemes, we ask: What is the systematic component of monetary policy associated with the set of models identified by Restriction 6. The first row of Table 3 responds to this question. By construction, and since the zero restrictions are not imposed, the set of models that satisfy Restriction 6 implies $\psi_{y} \neq 0, \psi_{p} \neq 0$, and $\psi_{p_{c}} \neq 0$, thus violating Restriction 4 . Hence, if we only impose Restriction 6 , we obtain that $\mathrm{P}\left(\psi_{y} \neq 0\right)$ $=\mathrm{P}\left(\psi_{p} \neq 0\right)=\mathrm{P}\left(\psi_{p_{c}} \neq 0\right)=1$. The probability of drawing a negative coefficient on money and violating Restriction 5 is 0.18 . This last probability indicates that, even using money instead of reserves, Uhlig s (2005) agnostic identification scheme, represented by Restriction 6, implies a counterfactual systematic component of monetary policy that violates Restrictions 4 and 5 with 0.18 probability. As a consequence, the shocks identified by Restriction 6 are not monetary policy shocks.

\begin{tabular}{|c|c|c|c|c|}
\hline & $\mathrm{P}\left(\psi_{y} \neq 0\right)$ & $\mathrm{P}\left(\psi_{p} \neq 0\right)$ & $\mathrm{P}\left(\psi_{p_{c}} \neq 0\right)$ & $\mathrm{P}\left(\psi_{m}<0\right)$ \\
\hline Restriction 6 & 1.00 & 1.00 & 1.00 & 0.18 \\
\hline Restrictions 4 and 6 & 0.00 & 0.00 & 0.00 & 0.00 \\
\hline
\end{tabular}

Table 3: Probability of Violating Restrictions on the Systematic Component of Monetary Policy

What if we give a best possible chance to Uhlig s (2005) sign restrictions and use Restrictions 4 and 6 at the same time? As shown in the second row of Table 3 , when this is the case the restriction on the sign of $\psi_{m}$ is always satisfied.

What are the consequences for the IRFs? As Figure 14 emphasizes, when we impose Restrictions 4 and 6 , the response of output to a monetary policy shock is negative and the consensus is recovered. 

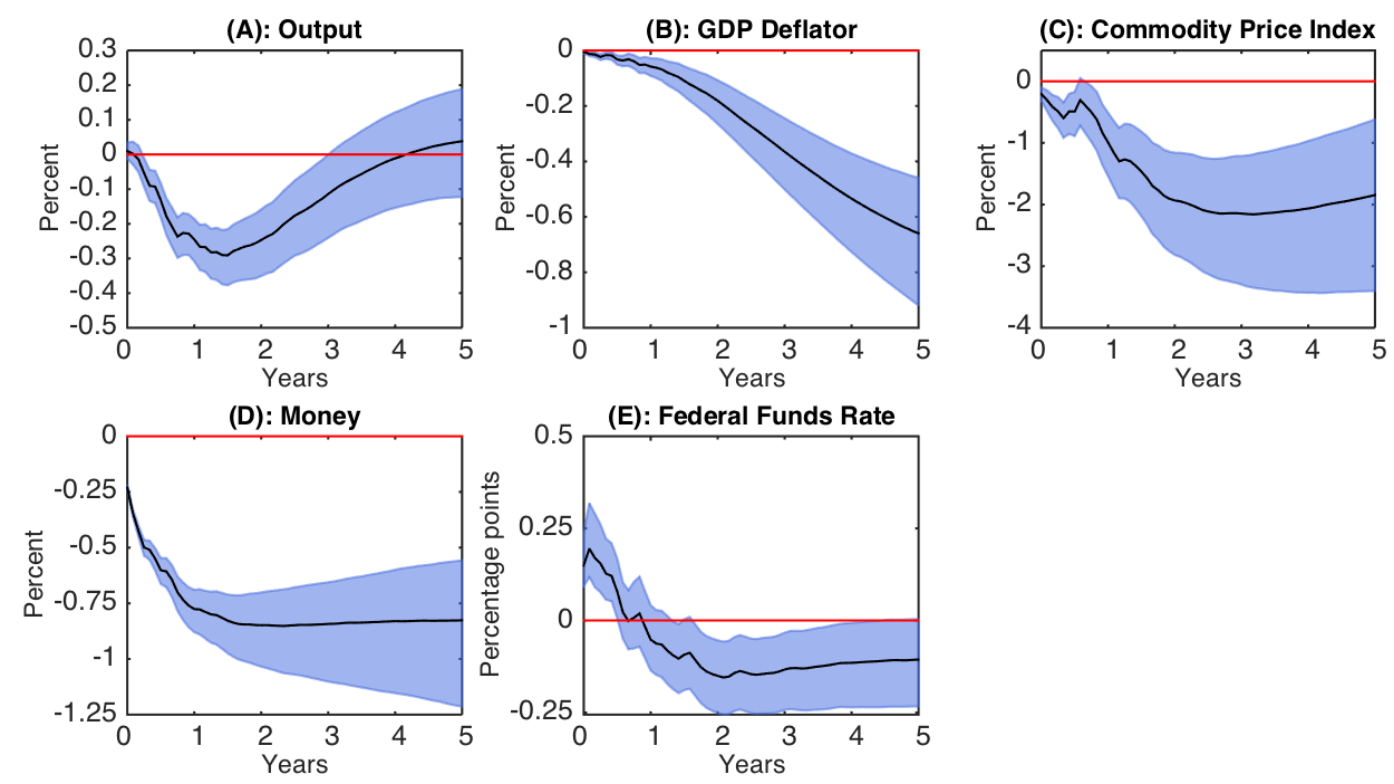

Figure 14: IRFs to a Monetary Policy Shock Identified Using Restrictions 4 and 6

It is true that there are some minimal differences between Figures 12 and 14 ? The drop in output is now less persistent, as it converges to its pre-shock level after three and a half years, and the path for the federal funds rate is somewhat different in the latter figure, since the initial increase is about 20 basis points lower and it remains positive for around 6 months. The differences in the path for the federal funds rate can be rationalized by the more negative response of the GDP deflator, which eliminates the upward pressure on the federal funds rate generated by the price puzzle.

The results obtained using Restrictions 4 and 6 again show that our restrictions substantially shrink the set of models identified by Uhlig (2005), and that excluding models with counterfactual monetary policy equations suffices to generate a negative response of output and thereby recover the consensus.

Overall, the evidence presented in this section confirms the results in Section 3 . Hence, even if we consider monetary policy equations represented by money rules, output declines after a contractionary monetary policy shock and Uhlig s (2005) agnostic identification scheme produces counterfactual monetary policy equations. 


\subsection{A Money Rule with Commodity Prices}

In some cases, as in Leeper and Zha (2003), the federal funds rate is allowed to respond to commodity prices in addition to money. In order to create a parallel with the results presented in Section 4, and because Leeper and Zha (2003) estimate a positive coefficient on commodity prices, we consider two cases: one in which the response of the federal funds rate to commodity prices $\psi_{p_{c}}$ is left unrestricted, and another in which the response of the federal funds rate to commodity prices is restricted to be positive $\left(\psi_{p_{c}} \geq 0\right)$. Before proceeding with these cases we need to introduce the following restriction that will replace Restriction 4.

Restriction 7. The federal funds rate is the monetary policy instrument and it only reacts contemporaneously to money and commodity prices.
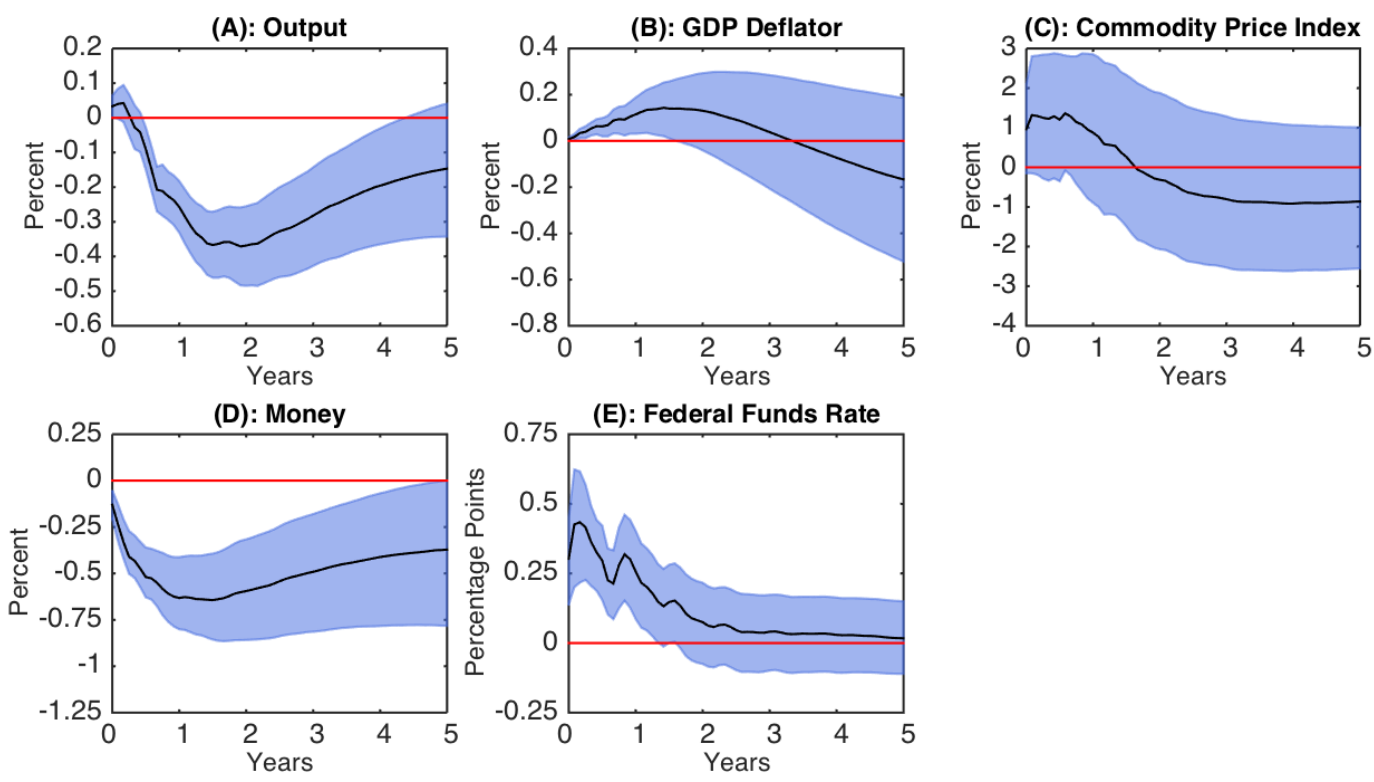

Figure 15: IRFs to a Monetary Policy Shock Identified Using Restrictions 5 and 7

Figures 15 and 16 plot the IRFs to a one standard deviation monetary policy shock when using Restrictions 5, 7, and the two variants of the restriction on the response of the federal funds rate to commodity prices $-\psi_{p_{c}} \neq 0$ and $\psi_{p_{c}}>0$, respectively. The core feature of our results also emerges when we consider money rules that feature a non-zero response to commodity prices: Output drops following a contractionary monetary policy shock. 

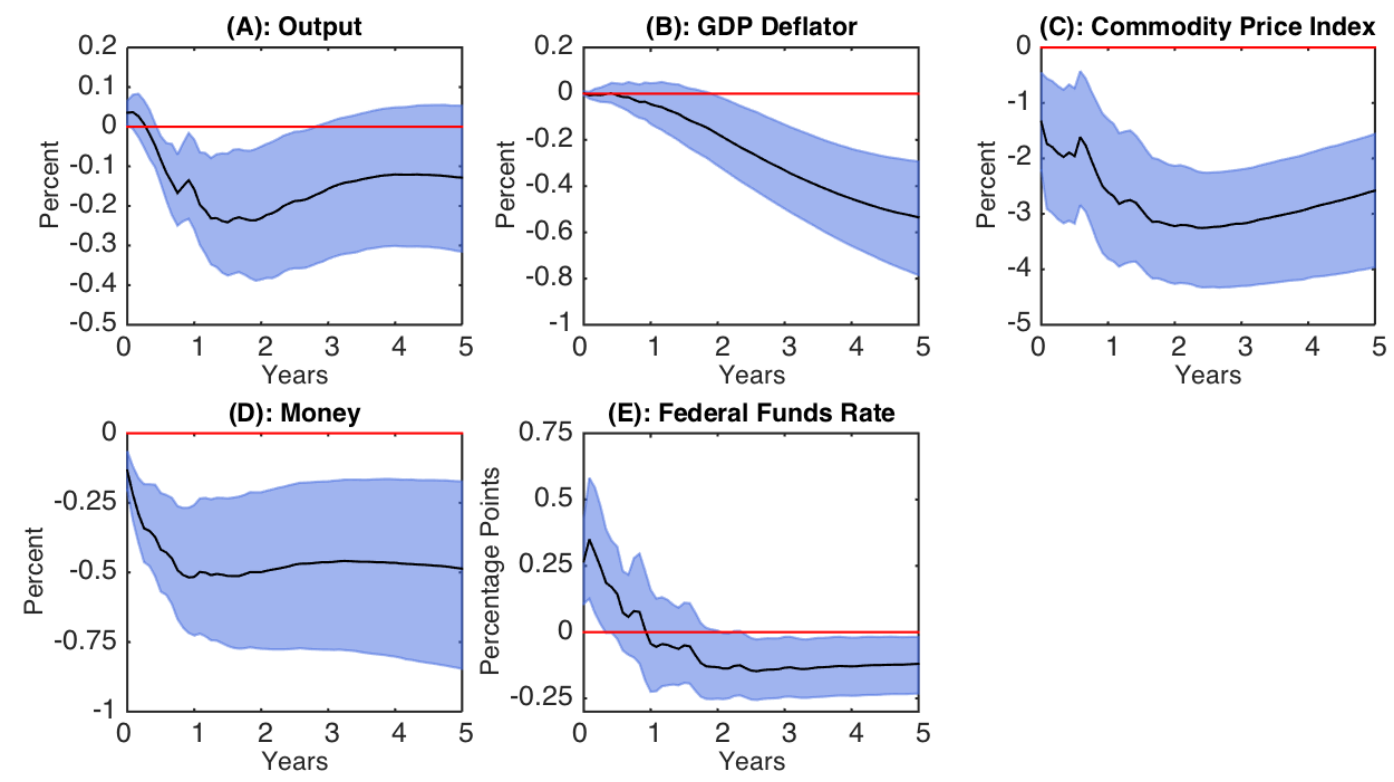

Figure 16: IRFs to a Monetary Policy Shock Identified Using Restrictions 5, 7, and $\psi_{p_{c}}>0$

\section{Conclusion}

The agnostic identification scheme of monetary policy shocks proposed by Uhlig (2005) finds that increases in the federal funds rate are not contractionary. We re-examine this issue and show that the identification scheme in Uhlig (2005) implies a counterfactual characterization of the systematic component of monetary policy. We design an agnostic identification scheme that imposes sign and zero restrictions on the systematic component of monetary policy and find that a monetary policy tightening leads to a persistent decline in output and prices.

Overall, our results suggest that while Uhlig) s (2005) set identification is appealing because it is agnostic and does not require inference to be based on very specific - and often questionable exclusion restrictions, it is subject to the danger of including implausible models. Our suggestion is to maintain agnosticity and set identification but to impose restrictions on the systematic component of monetary policy. Our approach excludes many implausible models while not requiring any questionable exclusion restrictions. The issue of how to specify agnostic restrictions in SVARs is not limited to the identification of monetary policy shocks, and the approach described in this paper can be applied to a variety of identification problems. 


\section{References}

Arias, J., J. F. Rubio-Ramirez, and D. F. Waggoner (2014): "Inference Based on SVARs Identified with Sign and Zero Restrictions: Theory and Applications," International Finance Discussion Papers 1100, Board of Governors of the Federal Reserve System.

Bagliano, F. C. And C. A. Favero (1998): "Measuring Monetary Policy with VAR Models: An Evaluation," European Economic Review, 42, 1069-1112.

Baumeister, C. And L. Benati (2010): "Unconventional Monetary Policy and the Great Recession: Estimating the Impact of a Compression in the Yield Spread at the Zero Lower Bound," Working Paper 1258, European Central Bank.

Baumeister, C. And J. Hamilton (2014): "Sign Restrictions, Structural Vector Autoregressions, and Useful Prior Information," Working Paper.

Beaudry, P., D. Nam, And J. Wang (2011): "Do Mood Swings Drive Business Cycles and is it Rational?" Working Paper 17651, National Bureau of Economic Research.

Belongia, M. T. And P. N. Ireland (2014): "Interest Rates and Money in the Measurement of Monetary Policy," Working Paper 20134, National Bureau of Economic Research.

Bernanke, B. S. And A. S. Blinder (1992): "The Federal Funds Rate and the Channels of Monetary Transmission," American Economic Review, 82, 901-21.

Bernanke, B. S., M. Gertler, M. Watson, C. A. Sims, and B. M. Friedman (1997): "Systematic Monetary Policy and the Effects of Oil Price Shocks," Brookings Papers on Economic Activity, 1997, 91-157.

Bernanke, B. S. And I. Mihov (1998): "Measuring Monetary Policy," Quarterly Journal of Economics, 113, 869-902.

Binning, A. (2013): "Underidentified SVAR Models: A Framework for Combining Short and Long-Run Restrictions with Sign-Restrictions," Norges Bank Working Paper. 
Caldara, D. and C. Kamps (2012): "The Analytics of SVAR: A Unified Framework to Measure Fiscal Multipliers," Finance and Economics Discussion Series 2012-20, Board of Governors of the Federal Reserve System.

Chappell Jr, H. W., R. R. McGregor, and T. A. Vermilyea (2005): Committee Decisions on Monetary Policy: Evidence from Historical Records of the Federal Open Market Committee, The MIT Press.

Christiano, L., M. Eichenbaum, And C. Evans (2005): "Nominal Rigidities and the Dynamic Effects of a Shock to Monetary Policy," Journal of Political Economy, 113, 1-45.

Christiano, L. J., M. Eichenbaum, And C. L. Evans (1996): "The Effects of Monetary Policy Shocks: Evidence from the Flow of Funds," Review of Economics and Statistics, 78, 16-34.

_ (1999): "Monetary Policy Shocks: What Have we Learned and to What End?" Handbook of Macroeconomics, 1, 65-148.

Faust, J. (1998): "The Robustness of Identified VAR Conclusions about Money," CarnegieRochester Conference Series on Public Policy, 49, 207-244.

Inoue, A. AND L. Kilian (2013): "Inference on Impulse Response Functions in Structural VAR Models," Journal of Econometrics, 177, 1-13.

Leeper, E. M. And D. B. Gordon (1992): "In Search of the Liquidity Effect," Journal of Monetary Economics, 29, 341-369.

Leeper, E. M., C. A. Sims, And T. Zha (1996): "What Does Monetary Policy Do?" Brookings Papers on Economic Activity, 27, 1-78.

Leeper, E. M. And T. Zha (2003): "Modest Policy Interventions," Journal of Monetary Economics, 50, 1673-1700.

Mönch, E. And H. Uhlig (2005): "Towards a Monthly Business Cycle Chronology for the Euro Area," Journal of Business Cycle Measurement and Analysis, 2, 43-69. 
Mountford, A. And H. Uhlig (2009): "What are the Effects of Fiscal Policy Shocks?" Journal of Applied Econometrics, 24, 960-992.

Peersman, G. And W. B. Wagner (2014): "Shocks to Bank Lending, Risk-Taking, Securitization, and Their Role for U.S. Business Cycle Fluctuations," Discussion Paper 2014-019, Tilburg University, Center for Economic Research.

Romer, C. D. And D. H. Romer (2004): "A New Measure of Monetary Shocks: Derivation and Implications," American Economic Review, 94, 1055-1084.

Rotemberg, J. And M. Woodford (1997): "An Optimization-based Econometric Framework for the Evaluation of Monetary Policy," NBER Macroeconomics Annual 1997, 12, 297-361.

Rubio-Ramírez, J., D. Waggoner, And T. Zha (2010): "Structural Vector Autoregressions: Theory of Identification and Algorithms for Inference," Review of Economic Studies, 77, 665-696.

Sims, C. A. (1972): "Money, Income, and Causality," American Economic Review, 62, 540-552.

- (1980): "Macroeconomics and Reality," Econometrica, 48, 1-48.

[ (1986): “Are Forecasting Models Usable for Policy Analysis?" Federal Reserve Bank of Minneapolis Quarterly Review, 10, 2-16.

- (1992): "Interpreting the Macroeconomic Time Series Facts: The Effects of Monetary Policy," European Economic Review, 36, 975-1000.

Sims, C. A. And T. Zha (2006a): "Does Monetary Policy Generate Recessions?" Macroeconomic Dynamics, 10, 231-272.

- (2006b): "Were There Regime Switches in US Monetary Policy?" American Economic Review, 96, 54-81.

Uhlig, H. (2005): "What are the Effects of Monetary Policy on Output? Results from an Agnostic Identification Procedure," Journal of Monetary Economics, 52, 381-419.

Waggoner, D. F. And T. Zha (2003): "Likelihood Preserving Normalization in Multiple Equation Models," Journal of Econometrics, 114, 329-347. 